\title{
Phenolic Thiazoles with Antioxidant and Antiradical Activity. Synthesis, In Vitro Evaluation, Toxicity, Electrochemical Behavior, Quantum Studies and Antimicrobial Screening
}

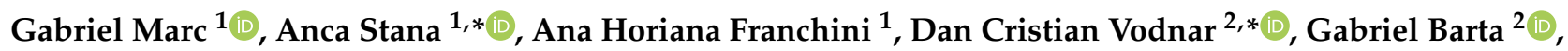 \\ Mihaela Tertiş ${ }^{3}{ }^{(0)}$, Iulia Şanta ${ }^{3}$, Cecilia Cristea ${ }^{3}{ }^{-}$, Adrian Pîrnău $\left.{ }^{4}{ }^{(}\right)$, Alexandra Ciorîţă ${ }^{4,5}$, Bogdan Dume ${ }^{5}$, \\ Vlad-Alexandru Toma ${ }^{4,5,6}$, Laurian Vlase ${ }^{7}$ (D) , Ilioara Oniga ${ }^{8}{ }^{(1)}$ and Ovidiu Oniga ${ }^{1}$
}

1 Department of Pharmaceutical Chemistry, "Iuliu Hațieganu" University of Medicine and Pharmacy, 41 Victor Babeș Street, RO-400012 Cluj-Napoca, Romania; marc.gabriel@umfcluj.ro (G.M.); ana.ho.franchini@elearn.umfcluj.ro (A.H.F.); ooniga@umfcluj.ro (O.O.)

2 Department of Food Science and Technology, University of Agricultural Sciences and Veterinary Medicine, 3-5 Manăştur Street, RO-400372 Cluj-Napoca, Romania; gabriel.barta@usamvcluj.ro

3 Department of Analytical Chemistry, Faculty of Pharmacy, "Iuliu Haţieganu" University of Medicine and Pharmacy, 4 Louis Pasteur Street, RO-400349 Cluj-Napoca, Romania; mihaela.tertis@umfcluj.ro (M.T.); iulia.nico.santa@elearn.umfcluj.ro (I.Ş.); ccristea@umfcluj.ro (C.C.)

4 National Institute for Research and Development of Isotopic and Molecular Technologies, 67-103 Donath Street, RO-400293 Cluj-Napoca, Romania; apirnau@itim-cj.ro (A.P.); alexandra.ciorita@itim-cj.ro (A.C.); vlad.toma@ubbcluj.ro (V.-A.T.)

check for updates

Citation: Marc, G.; Stana, A.; Franchini, A.H.; Vodnar, D.C.; Barta, G.; Tertiş, M.; Şanta, I.; Cristea, C.; Pîrnău, A.; Ciorîţă, A.; et al. Phenolic Thiazoles with Antioxidant and Antiradical Activity. Synthesis, In Vitro Evaluation, Toxicity, Electrochemical Behavior, Quantum Studies and Antimicrobial Screening. Antioxidants 2021, 10, 1707. https:// doi.org/10.3390/antiox10111707

Academic Editors: Andrea Pinto and Domenico Nuzzo

Received: 30 September 2021

Accepted: 22 October 2021

Published: 27 October 2021

Publisher's Note: MDPI stays neutral with regard to jurisdictional claims in published maps and institutional affiliations.

Copyright: (๑) 2021 by the authors. Licensee MDPI, Basel, Switzerland. This article is an open access article distributed under the terms and conditions of the Creative Commons Attribution (CC BY) license (https:// creativecommons.org/licenses/by/ $4.0 /)$.
5 Department of Molecular Biology and Biotechnologies, Babeș-Bolyai University, 4-6 Clinicilor Street, RO-400006 Cluj-Napoca, Romania; bogdan.dume@stud.ubbcluj.ro

6 NIRDBS Bucharest, Institute of Biological Research, 48 Republicii Street, RO-400015 Cluj-Napoca, Romania

7 Department of Pharmaceutical Technology and Biopharmaceutics, "Iuliu Hațieganu" University of Medicine and Pharmacy, 41 Victor Babeș Street, RO-400012 Cluj-Napoca, Romania; laurian.vlase@umfcluj.ro

8 Department of Pharmacognosy, "Iuliu Haţieganu" University of Medicine and Pharmacy, 12 Ion Creangă Street, RO-400010 Cluj-Napoca, Romania; ioniga@umfcluj.ro

* Correspondence: stana.anca@umfcluj.ro (A.S.); dan.vodnar@usamvcluj.ro (D.C.V.); Tel.: +40-264-450-529 (A.S.); +40-747-341-881 (D.C.V.)

Abstract: Oxidative stress represents the underlying cause of many chronic diseases in human; therefore, the development of potent antioxidant compounds for preventing or treating such conditions is useful. Starting from the good antioxidant and antiradical properties identified for the previously reported Dihydroxy-Phenyl-Thiazol-Hydrazinium chloride (DPTH), we synthesized a congeneric series of phenolic thiazoles. The radical scavenging activity, and the antioxidant and chelation potential were assessed in vitro, a series of quantum descriptors were calculated, and the electrochemical behavior of the synthesized compounds was studied to evaluate the impact on the antioxidant and antiradical activities. In addition, their antibacterial and antifungal properties were evaluated against seven aerobic bacterial strains and a strain of $C$. albicans, and their cytotoxicity was assessed in vitro. Compounds $\mathbf{5 a}-\mathbf{b}, \mathbf{7} \mathbf{a}-\mathbf{b}$ and $\mathbf{8} \mathbf{a}-\mathbf{b}$ presented remarkable antioxidant and antiradical properties, and compounds $5 \mathbf{a}-\mathbf{b}, 7 \mathbf{a}$ and $8 \mathbf{a}$ displayed good $\mathrm{Cu}^{+2}$ chelating activity. Compounds $7 \mathbf{a}$ and 8a were very active against $P$. aeruginosa ATCC 27853 compared to norfloxacin, and proved less cytotoxic than ascorbic acid against the human keratinocyte cell line (HaCaT cells, CLS-300493). Several phenolic compounds from the synthesized series presented excellent antioxidant activity and notable anti-Pseudomonas potential.

Keywords: polyphenols; thiazole; antioxidant activity; antiradical activity; synthesis; cytotoxicity; antimicrobial activity; quantum studies; electrochemical behavior

\section{Introduction}

Oxidation is a necessary physiological process taking place in all living organisms. However, an imbalance between the generation and build-up of reactive oxygen and 
nitrogen species (ROS and RNS) and the capacity of a biological system to neutralize these reactive radicals leads to increasing oxidative stress, a phenomenon that is thought to be the underlying cause for the pathogenesis of many chronic diseases in humans [1]. Although it is impossible to entirely avoid ROS and RNS exposure and oxidative stress, the protection against oxidative damage and chronic pathologies can be accomplished through various endogenous and exogenous antioxidants. Many natural or synthetic antioxidants (vitamin E, vitamin C, flavonoids, polyphenols, etc.) have been recently exploited due to their favorable effect against oxidative stress, which may prove useful for treating or preventing several human conditions caused by excessive oxidants and free radicals' production [2].

The very good antioxidant and antiradical properties identified for the compound Dihydroxy-Phenyl-Thiazol-Hydrazinium chloride (DPTH), developed by our team and named in this paper $\mathbf{5 a}$, were the starting point for the present research [3].

The structure of compound $\mathbf{5 a}$ (DPTH from our previous paper) includes a benzene ring substituted with two phenolic groups positioned at 1,3 and a thiazole ring connected to the benzene nucleus by a hydrazone moiety. The remarkable antioxidant and antiradical activity of the compound can be attributed to the two phenolic groups and/or the hydrazone moiety from its structure. The previously reported compound 5a has two methyl groups-one on the azomethine carbon atom and the other in position 4 of the thiazole ring - which represented the sites of chemical modulations in our present study (Figure 1).
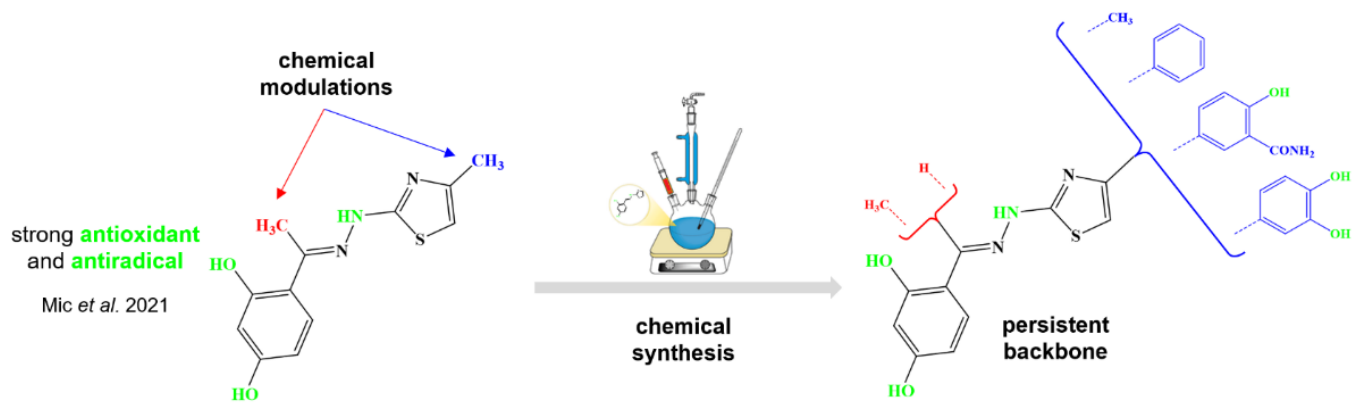

Figure 1. The hypothesis for the design of this research study.

Encouraged by the results obtained in the in vitro evaluations of the antioxidant and antiradical properties of compound $5 \mathbf{a}$, we set out to develop a complete congeneric series of eight compounds, based on the two types of substitutions we proposed $(2 \times 4$ elements of variability).

First, on the azomethine carbon atom, the compounds in the present study may have a methyl group (series a of compounds) or a hydrogen atom (series $\mathbf{b}$ of compounds). Therefore, we consider that this structural modulation is able to influence the antioxidant and antiradical activity of the compounds, because the hydrazone function was identified in a previous report as having significant antioxidant and antiradical activity due to the $\mathrm{N}-\mathrm{H}$ group [4].

The second structural modulation we propose is in position 4 of the thiazole ring. One mode of substitution is with a methyl group, which is electron donating (compounds $\mathbf{5 a - b}$ ); the second is with a phenyl ring, which is electron withdrawing (compounds 6a-b); and the third is with a phenyl ring substituted with phenolic groups (compounds $7 \mathbf{a}-\mathbf{b}$ and $\mathbf{8 a - b}$ ).

It is known from the literature that the conjugation of electrons is able to ensure a high stability of the structure resulting from a compound with antiradical properties following the neutralization of an external radical [5-7].

We proposed to perform these structural modulations because the backbone of the compounds allows multicenter electronic conjugation, so the effect of a substitution can be significantly manifested, not only on an antioxidant and/or antiradical group in its vicinity, but it can also influence the behavior of antioxidant and/or antiradical distal groups due to conjugation. 
Therefore, it was possible to evaluate the manner in which the antioxidant and antiradical activity of the compounds is influenced by the proposed substitutions.

The antioxidant and antiradical properties of the newly synthesized molecules were evaluated using several antiradical, electron transfer, and ferrous and cupric ions chelation assays. Moreover, a series of molecular quantum descriptors were determined in silico in order to assess their influence on the antioxidant and antiradical activities of the synthesized compounds, and their electrochemical behavior in terms of antioxidant character was studied.

The literature includes reports of researchers who synthesized compounds with a benzylidene-2-hydrazinyl thiazole structure, who made a number of interesting observations: compounds that have a nitrogen-type substituent (i.e., pyridine) or an $\mathrm{OH}$ group in the ortho position of the benzylidene moiety, have good antimicrobial or antimalarial activity compared to compounds that have the polar substituent elsewhere on the aromatic nucleus [8-10]. As phenolic compounds have been reported to possess good antimicrobial properties [11,12], we also evaluated the antibacterial and antifungal activity of the synthesized compounds.

In addition, their cytotoxicity was evaluated in vitro on a human keratinocyte cell line and their effect on the cells integrity was studied, in order to establish their safety for use in further biological activity investigations.

\section{Materials and Methods}

\subsection{Chemistry}

All chemicals and reagents used in the present research had appropriate grade purity and were purchased from local suppliers. The melting points were measured using an MPM-H1 melting point device (Schorpp Gerätetechnik, Überlingen, Germany), using the glass capillary method. The MS spectra of the compounds were recorded on an Agilent 1100 series device, in negative ionization mode, connected to an Agilent Ion Trap SL mass spectrometer (Agilent Technologies, Santa Clara, CA, USA). The IR spectra were recorded under vacuum, using a FT/IR 6100 spectrometer (Jasco, Cremella, Italy) in KBr pellets. The ${ }^{1} \mathrm{H}-\mathrm{NMR}$ and ${ }^{13} \mathrm{C}$-NMR spectra were recorded using an Avance NMR spectrometer (Bruker, Karlsruhe, Germany) in dimethyl sulfoxide- $\mathrm{d}_{6}\left(\mathrm{DMSO}-\mathrm{d}_{6}\right)$. Chemical shift values were reported in $\delta$ units, using tetramethylsilane as an internal standard.

The route followed for synthesizing the intermediate and final compounds is presented in Scheme 1. The synthesis of intermediate compounds $\mathbf{3 a}$ and $\mathbf{3 b}$ and that of final compound $5 \mathbf{a}$ were previously reported in the literature $[3,13,14]$. To a methanol solution (60 $\mathrm{mL}$ ) of 2,4-dihydroxybenzaldehyde $\mathbf{1 b}$ or 2,4-dihydroxyacetophenone $1 \mathbf{a}(20 \mathrm{mmol})$ was added a hot aqueous solution $(30 \mathrm{~mL})$ of thiosemicarbazide $2(20 \mathrm{mmol})$ and to the resulted mixtures was added a drop of concentrated $\mathrm{H}_{2} \mathrm{SO}_{4}$. The reaction mixtures were refluxed for $2 \mathrm{~h}$ and afterwards they were cooled to room temperature. The resulting precipitates (compounds $\mathbf{3 a}$ and $\mathbf{3 b}$ ) were filtered off and vacuum dried. The synthesis of all final compounds was performed according to a method already described in the literature $[3,15]$. A quantity of $10 \mathrm{mmol}$ of compound $3 \mathbf{a}-\mathbf{b}$ was mixed with $70 \mathrm{~mL}$ of hot anhydrous acetone in a round bottom glass flask under magnetic stirring until solubilization, then $10 \mathrm{mmol}$ of the corresponding compound 4a-d was added. Afterwards, the mixture was refluxed for one hour in a steam bath. After reaction completion was confirmed by TLC, the reaction mixture was left with continuous stirring to cool in order to allow the total precipitation of the desired final product. The precipitate was filtered using vacuum and crystallized two times from anhydrous acetone $(2 \times 50 \mathrm{~mL})$, to obtain the final compounds $\mathbf{5} \mathbf{b}, \mathbf{6} \mathbf{a}-\mathbf{b}, \mathbf{7} \mathbf{a}-\mathbf{b}$, and $\mathbf{8 a - b}$. 


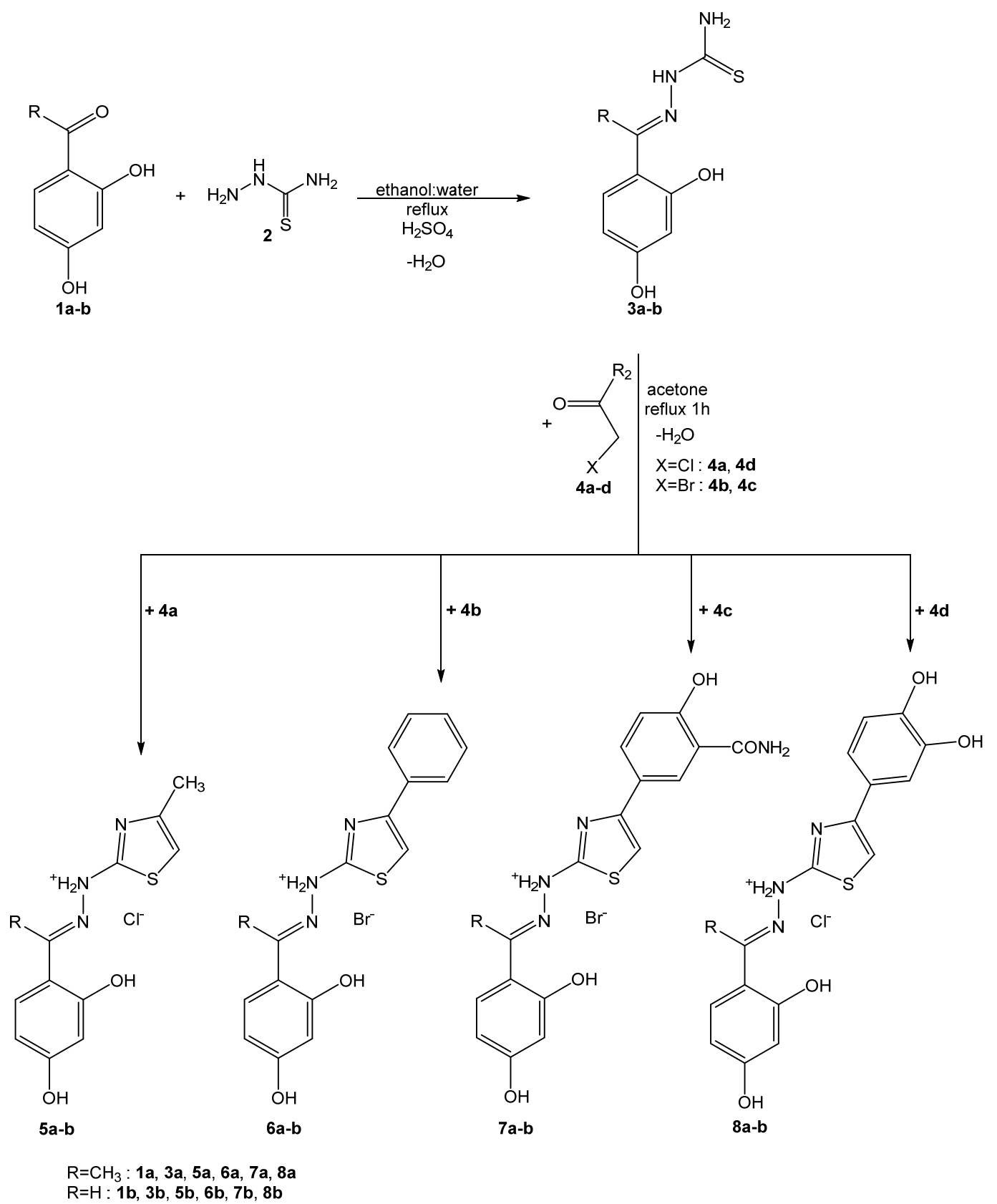

Scheme 1. The general route for the synthesis of target compounds.

The compounds' purity was initially confirmed by thin layer chromatography (TLC) and afterwards by high performance liquid chromatography (HPLC). (E)-2-(2,4-dihydroxybenzylidene)-1-(4-methylthiazol-2-yl)hydrazin-1-ium chloride (5b): white solid; carbonization over $240{ }^{\circ} \mathrm{C}$; yield $=71 \%$; FT IR $(\mathrm{KBr}) v_{\max } \mathrm{cm}^{-1}$ : $3425(\mathrm{OH}), 3197(\mathrm{NH}), 3100,2831$, 1627, 1614, $1520(\mathrm{C}=\mathrm{C}, \mathrm{C}=\mathrm{N}), 1361,1217(\mathrm{OH}), 971 ; \mathrm{MS}: \mathrm{m} / z=248.1 ;{ }^{1} \mathrm{H}-\mathrm{NMR}\left(\mathrm{DMSO}-\mathrm{d}_{6}\right.$, $500 \mathrm{MHz}) \delta: 2.236\left(\mathrm{~s}, 3 \mathrm{H},-\mathrm{CH}_{3}\right), 6.358(\mathrm{dd}, 1 \mathrm{H}, \mathrm{Ar}, J=8.5 \mathrm{~Hz}, J=2.5 \mathrm{~Hz}), 6.404(\mathrm{dd}, 1 \mathrm{H}, \mathrm{Ar}$, $J=2 \mathrm{~Hz}), 6.584$ (s, 1H, Th-C5), 7.560 (br, 1H, Ar), 8.488 (s, 1H, -CH=); ${ }^{13} \mathrm{C}-\mathrm{NMR}\left(\mathrm{DMSO}-\mathrm{d}_{6}\right.$, $125 \mathrm{MHz}$ ) 8: $14.850\left(-\mathrm{CH}_{3}\right), 100.962$ (Th-C5), 102.943 (Ar), 108.591 (Ar), 111.293 (Ar), 128.868 (Ar), 149.110 (-CH=), 159.182 (Ar-OH), 161.807 (Ar-OH), 167.329 (Th-C2).

(E)-2-(1-(2,4-dihydroxyphenyl)ethylidene)-1-(4-phenylthiazol-2-yl)hydrazin-1-ium bromide (6a): pale yellow solid; carbonization over $264{ }^{\circ} \mathrm{C}$; yield $=89 \%$; FT IR $(\mathrm{KBr}) v_{\max } \mathrm{cm}^{-1}$ : $3425(\mathrm{OH}), 3098(\mathrm{NH}), 1620,1567,1520(\mathrm{C}=\mathrm{C}, \mathrm{C}=\mathrm{N}), 1366,1329,1269,1149(\mathrm{OH}), 986$; MS: $m / z=325.2 ;{ }^{1} \mathrm{H}-\mathrm{NMR}\left(\mathrm{DMSO}_{6}, 500 \mathrm{MHz}\right) \delta: 2.393\left(\mathrm{~s}, 3 \mathrm{H},-\mathrm{CH}_{3}\right), 6.317(\mathrm{~d}, 1 \mathrm{H}, \mathrm{Ar}$, $J=2.5 \mathrm{~Hz}), 6.359(\mathrm{dd}, 1 \mathrm{H}, \mathrm{Ar}, J=9 \mathrm{~Hz}, J=2.5 \mathrm{~Hz}), 7.277(\mathrm{~s}, 1 \mathrm{H}, \mathrm{Th}-\mathrm{C} 5), 7.333(\mathrm{t}, 1 \mathrm{H}, \mathrm{Ar}$, 
$J=7.5 \mathrm{~Hz})$, 7.407-7.447 (m, 3H, Ar), $7.886(\mathrm{~d}, 2 \mathrm{H}, \mathrm{Ar}, J=7 \mathrm{~Hz}) ;{ }^{13} \mathrm{C}-\mathrm{NMR}\left(\mathrm{DMSO}-\mathrm{d}_{6}\right.$, $125 \mathrm{MHz})$ 8: $14.878\left(-\mathrm{CH}_{3}\right), 103.468(\mathrm{Ar}), 107.597(\mathrm{Ar}), 112.490(\mathrm{Ar}), 126.062(\mathrm{Ar}), 128.357$ (Ar), 129.062 (Ar), 130.044 (Ar), 159.882 (Ar-OH), 160.288 (Ar-OH), 168.225 (Th-C2).

(E)-2-(2,4-dihydroxybenzylidene)-1-(4-phenylthiazol-2-yl)hydrazin-1-ium bromide (6b): pale yellow solid; carbonization over $260{ }^{\circ} \mathrm{C}$; yield $=75 \%$; FT IR $(\mathrm{KBr}) v_{\max } \mathrm{cm}^{-1}$ : $3394(\mathrm{OH}), 3287(\mathrm{NH})$, 3066, 2923, 2831, 1632, 1616, 1579, 1564 (C=C, C=N), 1512, 1502, 1415, 1315, 1241, 1229, $1165(\mathrm{OH}), 1103,980,743 ; \mathrm{MS}: \mathrm{m} / \mathrm{z}=310.3 ;{ }^{1} \mathrm{H}-\mathrm{NMR}\left(\mathrm{DMSO}-\mathrm{d}_{6}\right.$, $500 \mathrm{MHz})$ 8: 6.349-6.381 (m, 2H, Ar), 7.302 (s, 1H, Th-C5), 7.422-7.471 (m, 3H, Ar), 7.348 $(\mathrm{t}, 1 \mathrm{H}, \mathrm{Ar}, J=7.5 \mathrm{~Hz}), 7.825(\mathrm{~d}, 2 \mathrm{H}, \mathrm{Ar}, J=8.5 \mathrm{~Hz}), 8.38(\mathrm{~s}, 1 \mathrm{H},-\mathrm{CH}=) ;{ }^{13} \mathrm{C}-\mathrm{NMR}$ (DMSO$\left.\mathrm{d}_{6}, 125 \mathrm{MHz}\right)$ 8: 102.985 (Th-C5), 103.734 (Ar), 108.493 (Ar), 111.790 (Ar), 126.292 (Ar), 128.588 (Ar), 129.169 (Ar), 133.537 (Ar), 143.665 (-CH=), $158.517(\mathrm{Ar}-\mathrm{OH}), 160.981$ (Ar-OH), 168.428 (Th-C2).

(E)-1-(4-(3-carbamoyl-4-hydroxyphenyl)thiazol-2-yl)-2-(1-(2,4-dihydroxyphenyl) ethylidene)hydrazin-1-ium bromide (7a): pale yellow solid; carbonization over $290^{\circ} \mathrm{C}$; yield $=78 \%$; FT IR (KBr) $\gamma_{\max } \mathrm{cm}^{-1}$ : $3382(\mathrm{OH}), 3275(\mathrm{OH}), 3202(\mathrm{NH})$, 3099, 2947, 2832, 1659, 1624, 1587, $1554(\mathrm{C}=\mathrm{C}, \mathrm{C}=\mathrm{N}), 1518,1442,1368,1215(\mathrm{OH}), 1126,1007,835 ; \mathrm{MS}: \mathrm{m} / \mathrm{z}=383.4$; ${ }^{1} \mathrm{H}-\mathrm{NMR}\left(\mathrm{DMSO}_{\mathrm{d}}, 500 \mathrm{MHz}\right) \delta: 2.392\left(\mathrm{~s}, 3 \mathrm{H},-\mathrm{CH}_{3}\right), 6.315(\mathrm{~d}, 1 \mathrm{H}, \mathrm{Ar}, J=2.5 \mathrm{~Hz}), 6.360$ $(\mathrm{dd}, 1 \mathrm{H}, \mathrm{Ar}, J=2.5 \mathrm{~Hz}, J=8.5 \mathrm{~Hz}), 6.954(\mathrm{~d}, 1 \mathrm{H}, \mathrm{Ar}, J=8.5 \mathrm{~Hz}), 7.115(\mathrm{~s}, 1 \mathrm{H}, \mathrm{Th}-\mathrm{C} 5), 7.415$ $(\mathrm{d}, 1 \mathrm{H}, \mathrm{Ar}, J=9 \mathrm{~Hz}), 7.893(\mathrm{dd}, 1 \mathrm{H}, \mathrm{Ar}, J=2.5 \mathrm{~Hz}, J=8.5 \mathrm{~Hz}), 7.967(\mathrm{br}, 1 \mathrm{H},-\mathrm{NH}), 8.358$ (s, 1H, Ar), 8.449 (br, $1 \mathrm{H},-\mathrm{NH}) ;{ }^{13} \mathrm{C}-\mathrm{NMR}\left(\mathrm{DMSO}-\mathrm{d}_{6}, 125 \mathrm{MHz}\right) \delta: 14.906\left(-\mathrm{CH}_{3}\right), 103.454$ (Ar), 107.618 (Ar), 112.483 (Ar), 115.192 (Ar), $118.033\left(\mathrm{Ar}-\mathrm{CONH}_{2}\right), 126.118$ (Ar), 130.072 (Ar), 131.808 (Ar), 159.903 (Ar-OH), 160.316 (Ar-OH), 160.981 (Ar-OH), 166.267 (Th-C2), $172.152\left(-\mathrm{CONH}_{2}\right)$.

(E)-1-(4-(3-carbamoyl-4-hydroxyphenyl)thiazol-2-yl)-2-(2,4-dihydroxybenzylidene) hydrazin-1-ium bromide (7b): pale yellow solid; carbonization over $260{ }^{\circ} \mathrm{C}$; yield $=71 \%$; FT IR (KBr) $v_{\max } \mathrm{cm}^{-1}: 3397(\mathrm{OH}), 3283(\mathrm{NH}), 3198,3134,2831,1673,1629,1611,1584$ $(\mathrm{C}=\mathrm{C}, \mathrm{C}=\mathrm{N}), 1367,1217(\mathrm{OH}), 1119,1005,977,774 ; \mathrm{MS}: \mathrm{m} / \mathrm{z}=369.4 ;{ }^{1} \mathrm{H}-\mathrm{NMR}\left(\mathrm{DMSO}-\mathrm{d}_{6}\right.$, $500 \mathrm{MHz}) \delta: 6.337-6.360(\mathrm{~m}, 2 \mathrm{H}, \mathrm{Ar}), 6.941$ (d, 1H, Ar, $J=9 \mathrm{~Hz}), 7.124(\mathrm{~s}, 1 \mathrm{H}, \mathrm{Th}-\mathrm{C} 5), 7.422$ $(\mathrm{d}, 1 \mathrm{H}, \mathrm{Ar}, J=9 \mathrm{~Hz}), 7.866(\mathrm{dd}, 1 \mathrm{H}, \mathrm{Ar}, J=8.5 \mathrm{~Hz}, J=2 \mathrm{~Hz}), 7.942(\mathrm{br}, 1 \mathrm{H},-\mathrm{NH}), 8.262(\mathrm{~s}, 1 \mathrm{H}$, $-\mathrm{CH}=), 8.232(\mathrm{~d}, 1 \mathrm{H}, \mathrm{Ar}, J=2 \mathrm{~Hz}), 8.480(\mathrm{br}, 1 \mathrm{H},-\mathrm{NH}) ;{ }^{13} \mathrm{C}-\mathrm{NMR}\left(\mathrm{DMSO}_{-} \mathrm{d}_{6}, 125 \mathrm{MHz}\right) \delta$ : 101.473 (Th-C5), 102.978 (Ar), 108.402 (Ar), 111.937 (Ar), 115.192 (Ar), 117.956 (Ar), 126.125 (Ar), $128.973(\mathrm{Ar}), 131.906(\mathrm{Ar}), 142.776(-\mathrm{CH}=), 158.349(\mathrm{Ar}-\mathrm{OH}), 160.673(\mathrm{Ar}-\mathrm{OH}), 160.869$ (Ar-OH), 168.414 (Th-C2), $172.201\left(-\mathrm{CONH}_{2}\right)$.

(E)-2-(1-(2,4-dihydroxyphenyl)ethylidene)-1-(4-(3,4-dihydroxyphenyl)thiazol-2-yl)hydrazin-1-ium chloride (8a): yellow solid; carbonization over $260{ }^{\circ} \mathrm{C}$; yield $=83 \%$; FT IR (KBr) $v_{\max } \mathrm{cm}^{-1}: 3401(\mathrm{OH}), 3184(\mathrm{NH}), 3163,1615,1600,1516(\mathrm{C}=\mathrm{C}, \mathrm{C}=\mathrm{N}), 1359,1282$, $1238(\mathrm{OH}), 1198,1178,1112,847,808,618$; MS: $\mathrm{m} / \mathrm{z}=356.5 ;{ }^{1} \mathrm{H}-\mathrm{NMR}\left(\right.$ DMSO-d $\left._{6}, 500 \mathrm{MHz}\right)$ $\delta: 2.394\left(\mathrm{~s}, 3 \mathrm{H},-\mathrm{CH}_{3}\right), 6.318(\mathrm{~d}, 1 \mathrm{H}, \mathrm{Ar}, J=2.5 \mathrm{~Hz}), 6.359(\mathrm{dd}, 1 \mathrm{H}, \mathrm{Ar}, J=2.5 \mathrm{~Hz}, J=8.5 \mathrm{~Hz})$, $6.781(\mathrm{~d}, 1 \mathrm{H}, \mathrm{Ar}, J=8 \mathrm{~Hz}), 6.879(\mathrm{~s}, 1 \mathrm{H}, \mathrm{Th}-\mathrm{C} 5), 7.122(\mathrm{dd}, 1 \mathrm{H}, \mathrm{Ar}, J=2 \mathrm{~Hz}, J=8 \mathrm{~Hz})$, $7.218(\mathrm{~d}, 1 \mathrm{H}, \mathrm{Ar}, J=2 \mathrm{~Hz}) ;{ }^{13} \mathrm{C}-\mathrm{NMR}\left(\mathrm{DMSO}-\mathrm{d}_{6}, 125 \mathrm{MHz}\right)$ 8: $14.969\left(-\mathrm{CH}_{3}\right), 103.447(\mathrm{Ar})$, 107.597 (Ar), 112.525 (Ar), 113.834 (Ar), 116.165 (Ar), 117.634 (Ar), 127.958 (Ar), 130.044 (Ar), 145.771 (Ar-OH), 146.233 (Ar-OH), 159.917 (Ar-OH), 160.323 (Ar-OH), 168.085 (Th-C2).

(E)-2-(2,4-dihydroxybenzylidene)-1-(4-(3,4-dihydroxyphenyl)thiazol-2-yl)hydrazin-1ium chloride (8b): orange solid; carbonization over $260{ }^{\circ} \mathrm{C}$; yield $=74 \%$; FT IR (KBr) $v_{\max } \mathrm{cm}^{-1}: 3379(\mathrm{OH}), 3112(\mathrm{NH}), 1639,1623,1610,1532,1523(\mathrm{C}=\mathrm{C}, \mathrm{C}=\mathrm{N}), 1336,1303$, $1278(\mathrm{OH}), 1240,1222,849 ; \mathrm{MS}: \mathrm{m} / z=342.5 ;{ }^{1} \mathrm{H}-\mathrm{NMR}\left(\mathrm{DMSO}_{6}, 500 \mathrm{MHz}\right) \delta: 6.358(\mathrm{dd}$, $1 \mathrm{H}, \mathrm{Ar}, J=2.5 \mathrm{~Hz}, J=8 \mathrm{~Hz}), 6.391(\mathrm{~d}, 1 \mathrm{H}, \mathrm{Ar}, J=2.5 \mathrm{~Hz}), 6.978(\mathrm{~d}, 1 \mathrm{H}, \mathrm{Ar}, J=8 \mathrm{~Hz}), 6.957$ (s, 1H, Th-C5), $7.102(\mathrm{dd}, 1 \mathrm{H}, \mathrm{Ar}, J=2 \mathrm{~Hz}, J=8 \mathrm{~Hz}), 7.210(\mathrm{~d}, 1 \mathrm{H}, \mathrm{Ar}, J=2 \mathrm{~Hz}), 7.455(\mathrm{~d}$, $1 \mathrm{H}, \mathrm{Ar}, J=8 \mathrm{~Hz}), 8.362(\mathrm{~s}, 1 \mathrm{H},-\mathrm{CH}=) ;{ }^{13} \mathrm{C}-\mathrm{NMR}\left(\mathrm{DMSO}-\mathrm{d}_{6}, 125 \mathrm{MHz}\right) \delta: 100.647$ (Th-C5), 102.999 (Ar), 108.486 (Ar), 111.685 (Ar), 114.072 (Ar), 116.221 (Ar), 117.879 (Ar), $128.896(\mathrm{Ar})$, 145.778 (Ar-OH), 146.401 (Ar-OH), 158.650 (Ar-OH), 161.100 (Ar-OH), 168.113 (Th-C2). 


\subsection{In Vitro Antioxidant, Antiradical and Chelation Assays}

The stock solutions $(1 \mathrm{mg} / \mathrm{mL})$ of the reference compounds and of the tested compounds were prepared in dimethyl sulfoxide (DMSO). Supplementary dilutions in DMSO of the initial stock solutions were made, according to the needs of each assay.

Using an UV-VIS Jasco V-530 spectrophotometer (Jasco International Co., Tokyo, Japan), the in vitro assays were carried out using $10 \mathrm{~mm}$ single use plastic cuvettes. The compounds showed no absorption peaks near the wavelengths where the measurements were performed. All the assays were conducted in triplicate and the results are presented as averages.

\subsubsection{Antiradical Assays \\ $\mathrm{ABTS}^{++}$Radical Scavenging Assay}

The assay was based on the decolorization of green (2,2'-azinobis-(3-ethylbenzothiazoline-6-sulfonic acid) ABTS ${ }^{-+}$to ABTS, on the principle reported by Re et al. and was carried out according to our previously published research $[16,17]$.

Quantities of 10, 15, 20,30, and $50 \mu \mathrm{L}$ from the $0.1 \mathrm{mg} / \mathrm{mL}$ stock solutions in DMSO of the compounds and ascorbic acid, used as standard, were poured into cuvettes and the appropriate volume of DMSO was added until a total volume of $50 \mu \mathrm{L}$ was found in all cuvettes. Later, $1950 \mu \mathrm{L}$ of $\mathrm{ABTS}^{*+}$ reagent was added to all cuvettes and they were shaken for well over $10 \mathrm{~min}$ in the dark at room temperature. The absorbance of the resulted solutions found in cuvettes was determined spectrophotometrically at $\lambda=734 \mathrm{~nm}$. The ABTS scavenging activity of the compounds was calculated using the following Equation (1):

$$
\text { ABTS scavenging }(\%)=\frac{\text { control absorbance }- \text { sample absorbance }}{\text { control absorbance }} \times 100
$$

\section{DPPH' Radical Scavenging Assay}

The 2,2-diphenyl-1-picrylhydrazyl (DPPH') radical scavenging assay is based on the transfer of one hydrogen from the analyzed compound to the violet radical $\mathrm{DPPH}$. This will convert it to a yellow compound, the change in absorbance being proportional to the amount of DPPH' neutralized, according to Brand-Williams et al. [18,19].

The preparation of the $\mathrm{DPPH}^{\cdot}$ reagent was previously reported by our group [17]. To all cuvettes were added 10, 15, 20, 30, and $50 \mu \mathrm{L}$ from the $0.2 \mathrm{mg} / \mathrm{mL}$ stock solution of the analyzed compounds in DMSO, and trolox and ascorbic acid as reference compounds. Over the previous quantities, DMSO was added until a total volume of $50 \mu \mathrm{L}$ was obtained in all cuvettes, and $1950 \mu \mathrm{L}$ of $\mathrm{DPPH}^{*}$ solution was added to all cuvettes; then, they were shaken for well over $10 \mathrm{~min}$ in the dark at room temperature. The absorbances of the solutions were measured at $\lambda=517 \mathrm{~nm}$. The DPPH ${ }^{\cdot}$ radical scavenging activity of evaluated compounds was calculated using Equation (2):

$$
\text { DPPH scavenging }(\%)=\frac{\text { control absorbance }- \text { sample absorbance }}{\text { control absorbance }} \times 100
$$

\section{NO Radical Scavenging Assay}

Scavenging of the NO radical was performed according to some adapted protocols reported in the literature, based on the nitroprusside decomposition at physiological $\mathrm{pH}$ and colorimetric quantification of the resulted products using the Griess reaction [20-22].

Over $200 \mu \mathrm{L}$ of $10 \mathrm{mM}$ sodium nitroprusside, $100 \mu \mathrm{L}$ of test solutions $(1 \mathrm{mg} / \mathrm{mL}$ in DMSO), and $400 \mu \mathrm{L}$ phosphate-buffered saline (PBS, $\mathrm{pH}=7.4$ ) were added. The mixture was then incubated at room temperature for $150 \mathrm{~min}$ on a rotating shaker (GFL Gesellschaft für Labortechnik, Burgwedel, Germany). After that, $1 \mathrm{~mL}$ of sulfanilic acid $0.33 \%$ in $20 \%$ acetic acid was added and after $5 \mathrm{~min}, 1 \mathrm{~mL}$ of naphthylethylenediamine dichloride $0.1 \%$ was added to all test tubes. After $30 \mathrm{~min}$, the absorbance of the sample, given by the chromophore (azo dye) formed during the diazotization of nitrite ions resulting from decomposition of sodium nitroprusside with sulfanilic acid and coupled with 
naphthylethylenediamine, was measured at $546 \mathrm{~nm}$. The NO radical scavenging activity of the tested compounds was calculated using Equation (3):

$$
\text { NO. scavenging }(\%)=\frac{\text { control absorbance }- \text { sample absorbance }}{\text { control absorbance }} \times 100
$$

\subsubsection{Electron Transfer Assays}

Ferric Reducing Antioxidant Potential (FRAP) Assay

The reducing power of the tested compounds was determined using the FRAP assay, according to a modified method proposed initially by Benzie and Strain, which was previously reported by our group $[3,17,19,23]$. The reducing power of compounds was calculated as percent of the reference compounds, using Equation (4):

$$
\% \text { of control activity }=\frac{\text { sample absorbance }}{\text { reference absorbance }} \times 100
$$

Phosphomolybdate Assay for Total Antioxidant Capacity (TAC)

To determine the TAC of the tested compounds we used a procedure previously reported in the literature by our group $[3,17,22,24]$. The TAC of compounds was calculated using Equation (5):

$$
\% \text { of control activity }=\frac{\text { sample absorbance }}{\text { reference absorbance }} \times 100
$$

Reducing Power (RP) Assay

The followed protocol to assess the RP of compounds was previously reported by our group $[3,17,22,25]$. The RP of compounds was calculated using Equation (6):

$$
\% \text { of control activity }=\frac{\text { sample absorbance }}{\text { reference absorbance }} \times 100
$$

\subsubsection{Ferrous and Cupric Chelation Assays}

\section{$\mathrm{Fe}^{2+}$ Chelation Assay}

The protocol used for assessing $\mathrm{Fe}^{2+}$ chelating capacity of the compounds was adapted from a report of Benzie and Strain and previously reported by our group [3,23,26]. The iron(II) chelation ability of compounds was calculated using Equation (7):

$$
\text { iron chelation }(\%)=\frac{\text { control absorbance }- \text { sample absorbance }}{\text { control absorbance }} \times 100
$$

\section{$\mathrm{Cu}^{2+}$ Chelation Assay}

The protocol used for evaluating $\mathrm{Cu}^{2+}$ chelating activity of the compounds and the disodium salt of ethylenediaminetetraacetic acid $($ EDTA-Na 2$)$ was performed using the method presented by Wu et al. with some modifications [27,28]. For each compound, 100, $200,300,400$, and $500 \mu \mathrm{L}$ were taken from the stock solutions ( $1 \mathrm{mg} / \mathrm{mL}$ in DMSO) and DMSO was added, in order to obtain a total volume of $500 \mu \mathrm{L}$ in each test tube. Over them, $400 \mu \mathrm{L}$ of $3 \mathrm{mM} \mathrm{CuSO}_{4}$ solution in hexamine buffer $(10 \mathrm{mM}$ hexamine and $10 \mathrm{mM} \mathrm{KCl})$ was added. After energic shaking for over $5 \mathrm{~min}, 75 \mu \mathrm{L}$ of murexide $1 \mathrm{mM}$ and $2 \mathrm{~mL}$ of water were added, and after $3 \mathrm{~min}$ of incubation at room temperature, the absorbance was read at 485 and $520 \mathrm{~nm}$. The two wavelengths correspond to the absorbance of murexidecopper(II) complex and free murexide, respectively. The ratio between the two absorbances are proportional to the free copper(II) in solution. The copper chelation capacity of the compounds was calculated using Equation (8): 


$$
\text { copper chelation }(\%)=\frac{\left(\frac{A_{485}}{A_{520}}\right)_{\text {control }}-\left(\frac{A_{485}}{A_{520}}\right)_{\text {sample }}}{\left(\frac{A_{485}}{A_{520}}\right)_{\text {control }}} \times 100
$$

\subsection{Electrochemical Behavior of Compounds}

The evaluated compounds' stock solutions used were prepared at a concentration of $5 \mathrm{mM}$. To test their redox properties, dilutions of $0.5 \mathrm{mM}$ and $2 \mathrm{mM}$ were prepared in $0.1 \mathrm{M}$ $\mathrm{HClO}_{4}$ electrolyte ( $\mathrm{pH}=1.2$ ). Screen-printed electrodes (SPEs; Metrohm DropSens, Oviedo, Spain) (planar electrodes) with graphite and gold working electrodes were used. Cyclic voltammetry (CV) and differential pulse voltammetry (DPV) were the electrochemical methods applied. The experimental conditions for each test are mentioned near the corresponding data (Appendix A).

The antioxidant properties were evaluated in terms of their activity against some free radicals, and other compounds reported in the literature, relevant for this purpose, such as:

- ferric ions $\left(\mathrm{Fe}^{3+}\right)$ - used to test the reduction of the antioxidant character of the compounds;

- $\quad$ DPPH free radical- used to test the scavenging effect of the compounds on this radical;

- hydrogen peroxide $\left(\mathrm{H}_{2} \mathrm{O}_{2}\right)$ - used to test the scavenging effect of the synthesized molecules on this compound;

- 2,2,6,6-tetramethylpiperidinyl-1-oxy (TEMPO)—used to test the scavenging effect of the synthesized molecules on this compound.

\subsection{Theoretical Quantum Calculations}

Taking into account the structure of the compounds and the most common quantum parameters used to be correlated with the antioxidant and antiradical activity of the compounds, we were interested in calculating the energy of the frontier orbitals and the strength of the bonds that can be broken in order to release hydrogen atoms, also known as bond dissociation energy (BDE) [29-31].

In order to have a better view of the antioxidant and antiradical behavior of the compounds, and how this is influenced by the chemical substitutions made on the backbone of the compounds, some theoretical quantum parameters were calculated according to a previously reported procedure $[4,17]$.

\subsection{Antimicrobial Activity Evaluation}

For evaluating the antimicrobial activity of the compounds, seven aerobic microbial strains were used: S. aureus ATCC 25923, S. pyogenes ATCC 19615, P. aeruginosa ATCC 27853, S. enterica ISM 83/37, S. typhimurium ATCC 14028, E. coli ATCC 8739, E. coli ATCC 25922, and C. albicans ATCC 102310 obtained from Food Biotechnology Laboratory, Life Sciences Institute, University of Agricultural Sciences, and Veterinary Medicine Cluj Napoca, where the experiment was performed. The antimicrobial activity of the compounds was determined using a modified microdilution technique, and the followed protocol was previously reported [32].

\subsection{Cytotoxicity Studies}

\subsubsection{Cytotoxicity Determination}

To determine the cytotoxic action of the obtained compounds $\mathbf{5 a - b}, \mathbf{6 a - b}, \mathbf{7} \mathbf{a}-\mathbf{b}$, and $\mathbf{8} \mathbf{a}-\mathbf{b}$, a normal human keratinocytes cell line was used (HaCaT keratinocytes, CLS-300493, Eppelheim, Germany). HaCaT cells were cultured in Dulbecco's Modified Eagle Media (DMEM) supplemented with 1\% L-glutamine, 1\% penicillin-streptomycin, and 5\% fetal bovine serum. At $80 \%$ confluence, the cells were transferred to 96 well plates at a confluence of $12 \times 10^{3}$ cells / well and left to attach for $24 \mathrm{~h}$ at $37^{\circ} \mathrm{C}$ and $5 \% \mathrm{CO}_{2}$ in a humidified atmosphere. The selected compounds were tested in increasing concentrations with the 3-(4,5-dimethylthiazol-2-yl)-2,5-diphenyltetrazolium bromide (MTT) method, based on which the $\mathrm{IC}_{50}$ (the concentration at which $50 \%$ of the cells were affected) was calculated [33]. 
Each plate contained controls with culture media and compounds $\mathbf{5 a}-\mathbf{b}, \mathbf{b}, \mathbf{6} \mathbf{a}-\mathbf{b}, \mathbf{7} \mathbf{7} \mathbf{a}-\mathbf{b}$, and $\mathbf{8 a - b}$ without cells under the same tested concentrations, untreated controls, and positive controls (cells treated with $2 \%$ Tween 20 and $0.3 \% \mathrm{H}_{2} \mathrm{O}_{2}$ ), and one plate was incubated with ascorbic acid (AA) solution using the same concentration. After $24 \mathrm{~h}$, the culture media was replaced with $100 \mu \mathrm{L}$ of MTT solution at a final concentration of $5 \mu \mathrm{g} / \mathrm{mL} /$ well and left to interact with the cells for $2 \mathrm{~h}$ in the incubator. After this, the MTT solution was replaced with $100 \mu \mathrm{L}$ of isopropanol, left to dissolve the formazan crystals for $5 \mathrm{~min}$, and read at 550 and $630 \mathrm{~nm}$ using a BioTek Epoch plate reader (BioTek Instruments, Winooski, VT, USA) and Gen5 software (version 1.09).

The $\mathrm{IC}_{50}$ concentrations were calculated according to Equation (9) [34]:

$$
M C=\frac{y-c}{m}
$$

where $M C=$ median concentration, $y=50 \%, c=$ constant generated by the exponential fitting of the data, and $m=$ the coefficient calculated from the exponential fit of the data.

\subsubsection{HaCaT Cells Integrity Evaluation}

In order to evaluate the cellular effect of the compounds, a selection from the whole batch of compounds was made, according to the structure-toxicity relationship that could be observed from the cytotoxicity determination. Analyzing the $\mathrm{IC}_{50}$ values obtained, two structural observations were made: in position 4 of the thiazole ring of the compounds the phenyl substituent is more favorable to the methyl rest and is preferable for the compounds to be phenylethylidene derivatives (series a of compounds) rather than benzylidene derivatives (series $\mathbf{b}$ of compounds). Even if the $\mathbf{b}$ series of compounds presented some intermediate $\mathrm{IC}_{50}$ values for compounds $5 \mathbf{b}\left(\mathrm{IC}_{50}=50.34 \mu \mathrm{g} / \mathrm{mL}\right)$ and $7 \mathbf{b}\left(\mathrm{IC}_{50}=42.36 \mu \mathrm{g} / \mathrm{mL}\right)$, because of the high cytotoxicity of the compounds $6 \mathbf{b}\left(\mathrm{IC}_{50}<0.50 \mu \mathrm{g} / \mathrm{mL}\right)$ and $8 \mathbf{b}\left(\mathrm{IC}_{50}=8.54 \mu \mathrm{g} / \mathrm{mL}\right)$, the whole $\mathbf{b}$ series of compounds was considered to be promiscuous and unsafe due to cytotoxicity. This conclusion can be strengthened by the observations of previous reports that found 2-benzylidenehydrazineyl-thiazole derivatives to have significant cytotoxic activity $[4,35]$. Thus, compounds $\mathbf{6 a}, 7 \mathbf{a}$, and $\mathbf{8} \mathbf{a}$ were selected for evaluation of their influence on HaCaT cells integrity.

First, an acridine orange staining of the $\mathrm{HaCaT}$ cells was performed to investigate morphological features of the cells $\left(3 \times 10^{4}\right.$ cells / well $)$ after treatment with the selected compounds $\mathbf{6 a}, 7 \mathrm{a}$, and $\mathbf{8 a}$ at $\mathrm{IC}_{50}$ concentration for $24 \mathrm{~h}$. The cells were left to attach to $10 \mathrm{~mm} \varnothing$ glass slides for $24 \mathrm{~h}$, at a confluence of $3 \times 10^{4}$ cells / glass slide. The slides were incubated for $10 \mathrm{~min}$ in acridine orange $1 \mu \mathrm{M}$ in PBS $0.01 \mathrm{M}$, and then the slides were investigated with an epifluorescence microscope Optika 510LD1 with 5 MP CCD cameras at $525 \mathrm{~nm}$ (green filter).

Second, a biochemical assay was performed, where the lactate dehydrogenase (LDH) and catalase (CAT) activity were determined. From the culture media of the cells exposed to the compounds $\mathbf{6 a}, \mathbf{7 a}$, and $\mathbf{8} \mathbf{a}$, at the determined $\mathrm{IC}_{50}$ value, the determinations were performed by the kinetic method using an UV-Vis spectrophotometer according to previous procedures, at $24 \mathrm{~h}[36,37]$. All results obtained are expressed as mean \pm standard deviation (SD). Comparisons between multiple groups were made using one-way ANOVA followed by Bonferroni's post-hoc test. $p<0.05$ was considered statistically significant and was interpreted as follows: ${ }^{*} p<0.05$, ${ }^{* *} p<0.01$, ${ }^{* * *} p<0.001$ for comparison with $\mathrm{H}_{2} \mathrm{O}_{2}$ treatment and ${ }^{\#} p<0.05,{ }^{\# \#} p<0.01$, \#\#\# $p<0.001$ when the comparison was made with the AA treatment. Statistical analyses were undertaken using GraphPad Prism 5.

\subsection{Molecular Properties with Influence on the Pharmacokinetics of Compounds}

From the literature reports it is known that polyphenols have poor bioavailability and absorption. Bioavailability is a pharmacokinetic parameter dependent on many processes and influenced by molecular properties [38,39]. Using the Swiss ADME web tool, some molecular properties were calculated, such as octanol-water partition coefficient, topological polar surface area, gastrointestinal absorption after oral administration, 
and octanol-water partition coefficients, as part of Lipinski's rule of five [40-42]. pKa of the compounds was assessed using MolGpka [43]. The calculation of the molecular properties was performed for each parent compound of the final compounds $\mathbf{5} \mathbf{a}-\mathbf{b}, \mathbf{6} \mathbf{a}-\mathbf{b}, \mathbf{7} \mathbf{a}-\mathbf{b}$, and $\mathbf{8 a}-\mathbf{b}$, without the corresponding hydrohalide acid.

\section{Results and Discussion}

\subsection{Chemical Synthesis and Characterization of Compounds}

The thiosemicarbazones $\mathbf{3} \mathbf{a}-\mathbf{b}$ derived from resorcinol were synthesized by condensation of the corresponding thiosemicarbazide $\mathbf{2}$ and 2,4-dihydroxyacetophenone (1a) or 2,4-dihydroxybenzaldehyde (1b) following literature procedures $[13,14]$. The hydrazinylthiazole phenolic derivatives $5 a-b, 6 a-b, 7 a-b$, and $8 a-b$ were obtained via Hantzsch heterocyclisation of thiosemicarbazones $3 \mathbf{a}-\mathbf{b}$ with the corresponding $\alpha$-haloketones $4 \mathbf{a}-\mathbf{d}$ (Scheme 1) following a previously reported method [3]. The final compounds were synthesized in the form of their hydrochloride or hydrobromide salts. Compounds $3 \mathbf{a}-\mathbf{b}$ and $5 \mathbf{a}$ were previously reported in the literature $[3,13,14]$.

All final synthesized compounds presented high melting points due to the fact that they were salts with hydro acids.

The spectral data obtained for the synthesized compounds were consistent with the proposed structures. In the MS spectra of final compounds, the corresponding molecular peaks and the hydrazinyl-thiazole peak was found. In the IR spectra of all final compounds, broad signals were identified at about $3400 \mathrm{~cm}^{-1}$ due to the phenolic $\mathrm{O}-\mathrm{H}$ stretching and $\mathrm{O}-\mathrm{H}$ bending bands at $1250 \mathrm{~cm}^{-1}$. The $\mathrm{N}-\mathrm{H}$ stretching bands appearing at $3100-3300 \mathrm{~cm}^{-1}$ and at $1520-1530 \mathrm{~cm}^{-1}$ were identified absorption signals due to the $\mathrm{C}=\mathrm{C}$ and $\mathrm{C}=\mathrm{N}$ stretching.

In the ${ }^{1} \mathrm{H}-\mathrm{NMR}$ spectra of the synthesized compounds, all protons' expected signals were identified, with the corresponding multiplicity and the related coupling constants. The broad signals expected for the $\mathrm{O}-\mathrm{H}$ and $\mathrm{N}-\mathrm{H}$ protons in the range of 8.5-12 ppm were overlapped and difficult to assign to a specific group, and were integrated as a whole.

In the ${ }^{13} \mathrm{C}$-NMR spectra of the target compounds, the aromatic carbons bearing the phenol groups appeared at high values, between 145.771 and $161.807 \mathrm{ppm}$. The most de-shielded values were found for the amide carbon atom at 172.152-172.201 ppm in the ${ }^{13} \mathrm{C}-\mathrm{NMR}$ spectra of compounds $\mathbf{7} \mathbf{a}-\mathbf{b}$ and for the carbon atoms from position 2 of the thiazole ring at $166.267-168.428 \mathrm{ppm}$ in the ${ }^{13} \mathrm{C}-\mathrm{NMR}$ spectra of all final compounds.

The spectra of all synthesized compounds are provided in Supplementary Materials (Figures S1-S28).

\subsection{In Vitro Antioxidant, Antiradical and Chelation Assays}

The antioxidant potential of the molecules was evaluated based on the mechanisms possible for this activity, reported in the literature: hydrogen atom transfer, electron transfer, or chelation of transition metals [44]. Some of the in vitro laboratory protocols followed for the presented assays were undertaken at a semi-microscale level, according to our group's previous reports $[3,17,25]$. All measurements were carried out in triplicate and the results are presented as averages.

\subsubsection{Antiradical Assays}

The antiradical potential of compounds was determined spectrophotometrically as the capacity to scavenge $\mathrm{ABTS}^{\cdot+}, \mathrm{DPPH}^{\cdot}$ and $\mathrm{NO}^{\cdot}$ radicals.

\section{$\mathrm{ABTS}^{++}$Radical Scavenging Assay}

The capacity of the tested compounds and ascorbic acid to reduce ABTS ${ }^{\cdot+}$ is presented in Table 1. According to the results obtained in this assay, all the synthesized compounds presented important $\mathrm{ABTS}^{++}$radical scavenging properties, the most active compounds being $\mathbf{5 a}-\mathbf{b}, \mathbf{7 b}$, and $\mathbf{8} \mathbf{a}-\mathbf{b}$, with lower $\mathrm{IC}_{50}$ values than that of ascorbic acid, used as standard antioxidant. 
Table 1. Results of the ABTS ${ }^{++}$scavenging assay.

\begin{tabular}{|c|c|c|c|c|c|c|}
\hline \multirow{2}{*}{ Compound } & \multicolumn{5}{|c|}{$\%$ of ABTS $^{*+}$ Scavenged } & \multirow{2}{*}{$\begin{array}{c}\mathrm{IC}_{50} \\
(\mu \mathrm{g} / \mathrm{mL})\end{array}$} \\
\hline & $0.5 \mu \mathrm{g} / \mathrm{mL}$ & $0.75 \mu \mathrm{g} / \mathrm{mL}$ & $1 \mu \mathrm{g} / \mathrm{mL}$ & $1.5 \mu \mathrm{g} / \mathrm{mL}$ & $2.5 \mu \mathrm{g} / \mathrm{mL}$ & \\
\hline $5 \mathbf{a}$ & 32.42 * & $37.23 *$ & $41.36 *$ & $49.77 *$ & $70.60 *$ & $1.45 *$ \\
\hline $5 b$ & 35.55 & 41.10 & 48.40 & 66.50 & 98.09 & 1.00 \\
\hline $6 a$ & 4.75 & 7.92 & 12.68 & 22.21 & 36.01 & 3.34 \\
\hline $6 b$ & 11.67 & 17.45 & 19.83 & 28.56 & 42.53 & 2.97 \\
\hline $7 \mathbf{a}$ & 11.62 & 17.29 & 22.69 & 30.78 & 49.37 & 2.52 \\
\hline $7 \mathbf{b}$ & 25.42 & 30.15 & 36.50 & 49.20 & 69.53 & 1.60 \\
\hline $8 a$ & 25.40 & 33.32 & 41.07 & 58.72 & 90.97 & 1.25 \\
\hline $8 b$ & 40.09 & 44.44 & 50.79 & 66.66 & 96.82 & 0.91 \\
\hline Ascorbic acid & 9.56 & 14.32 & 20.61 & 38.24 & 64.58 & 1.97 \\
\hline
\end{tabular}

\section{DPPH' Radical Scavenging Assay}

The antiradical potential of compounds in comparison to reference compounds, ascorbic acid, and trolox, was determined spectrophotometrically, and the results are shown in Table 2. As can be observed from Table 2, compounds $\mathbf{5 a - b}, \mathbf{7 a}-\mathbf{b}$, and $\mathbf{8 a}-\mathbf{b}$ presented the best capacity to scavenge the DPPH' radical.

Table 2. Results of the DPPH' scavenging assay.

\begin{tabular}{|c|c|c|c|c|c|c|}
\hline \multirow{2}{*}{ Compound } & \multicolumn{5}{|c|}{$\%$ of DPPH' Scavenged } & \multirow{2}{*}{$\begin{array}{c}\mathrm{IC}_{50} \\
(\mu \mathrm{g} / \mathrm{mL})\end{array}$} \\
\hline & $1 \mu \mathrm{g} / \mathrm{mL}$ & $1.5 \mu \mathrm{g} / \mathrm{mL}$ & $2 \mu \mathrm{g} / \mathrm{mL}$ & $3 \mu \mathrm{g} / \mathrm{mL}$ & $5 \mu \mathrm{g} / \mathrm{mL}$ & \\
\hline $5 a$ & $13.11^{*}$ & $20.68 *$ & $28.87^{*}$ & $48.22 *$ & $79.92 *$ & $3.20 *$ \\
\hline $5 b$ & 16.46 & 24.42 & 34.44 & 52.10 & 87.08 & 2.90 \\
\hline $6 a$ & 5.90 & 9.07 & 12.87 & 19.88 & 38.13 & 6.56 \\
\hline $6 b$ & 10.60 & 13.62 & 17.23 & 23.89 & 41.22 & 6.23 \\
\hline $7 \mathbf{a}$ & 20.01 & 22.10 & 26.75 & 32.43 & 49.27 & 5.19 \\
\hline $7 \mathbf{b}$ & 24.01 & 26.00 & 30.41 & 35.81 & 51.80 & 4.84 \\
\hline $8 a$ & 25.05 & 31.43 & 36.02 & 47.13 & 68.90 & 3.26 \\
\hline $8 b$ & 39.38 & 47.41 & 54.37 & 67.84 & 91.38 & 1.72 \\
\hline Ascorbic acid & 19.39 & 29.10 & 38.27 & 53.42 & 80.28 & 2.89 \\
\hline Trolox & 10.83 & 17.10 & 20.56 & 31.91 & 53.67 & 4.68 \\
\hline
\end{tabular}

* Data were reported previously [3].

\section{NO Radical Scavenging Assay}

The NO antiradical potential of compounds, gentisic acid, and trolox were evaluated spectrophotometrically, based on the Griess reaction and the obtained results are presented in Table 3. According to the results obtained in this assay, all compounds presented antiradical properties, compounds $\mathbf{5} \mathbf{a}-\mathbf{b}$ and $\mathbf{8 a}-\mathbf{b}$ displaying the best ability to scavenge the $\mathrm{NO}^{\circ}$ radical, superior to that of trolox, which was used as a reference.

Table 3. Results of the NO` scavenging assay.

\begin{tabular}{cc}
\hline Compound & \% of NO Scavenged \\
\hline $\mathbf{5 a}$ & 36.26 \\
$\mathbf{5 b}$ & 35.63 \\
$\mathbf{6 a}$ & 20.58 \\
$\mathbf{6 b}$ & 28.35 \\
$\mathbf{7 a}$ & 21.44 \\
$\mathbf{7 b}$ & 26.33 \\
$\mathbf{8 a}$ & 32.72 \\
$\mathbf{8 b}$ & 46.30 \\
Gentisic acid & 47.33 \\
Trolox & 32.12 \\
\hline
\end{tabular}




\subsubsection{Electron Transfer Assays}

The antioxidant capacity of the synthesized compounds calculated as capacity of donation of electrons was ascertained spectrophotometrically, based on the FRAP, TAC, and RP assays.

\section{Ferric Reducing Antioxidant Potential (FRAP) Assay}

In this assay, the evaluated compounds reduced the ferric ions to ferrous ions, yielding a blue-colored complex at $\mathrm{pH}=3.6$ with 2,4,6-tris(2-pyridyl)-s-triazine (TPTZ). The intensity of the blue color is related with the capacity of the compound to reduce the ferric ions. The results are presented in Table 4 and reveal that compounds $5 \mathbf{a}-\mathbf{b}, \mathbf{7} \mathbf{a}-\mathbf{b}$, and $\mathbf{8 a -} \mathbf{b}$ presented the best antioxidant potential.

Table 4. Results of the Ferric Reducing Antioxidant Potential (FRAP), Total Antioxidant Capacity (TAC), and Reducing Power (RP) assays, expressed as \% activity of ascorbic acid and trolox.

\begin{tabular}{ccccccc}
\hline \multirow{2}{*}{ Compound } & \multicolumn{2}{c}{$\%$ of Activity of Ascorbic Acid } & \multicolumn{3}{c}{$\%$ of Activity of Trolox } \\
\cline { 2 - 7 } & FRAP & TAC & RP & FRAP & TAC & RP \\
\hline $\mathbf{5 a}$ & $108.32 *$ & $120.58^{*}$ & $74.29 *$ & $257.96^{*}$ & $191.31 *$ & $187.87 *$ \\
$\mathbf{5 b}$ & 111.30 & 144.79 & 76.28 & 230.74 & 212.14 & 192.51 \\
$\mathbf{6 a}$ & 44.79 & 49.90 & 23.03 & 97.65 & 73.11 & 58.11 \\
$\mathbf{6 b}$ & 48.24 & 73.53 & 24.47 & 105.18 & 107.73 & 61.77 \\
$\mathbf{7 a}$ & 72.14 & 95.10 & 43.73 & 157.28 & 139.34 & 110.36 \\
$\mathbf{7 b}$ & 80.05 & 109.59 & 45.90 & 174.53 & 160.56 & 115.84 \\
$\mathbf{8 a}$ & 86.34 & 136.68 & 76.08 & 173.34 & 200.25 & 192.01 \\
$\mathbf{8 b}$ & 99.71 & 150.48 & 85.03 & 215.31 & 220.47 & 214.58 \\
\hline
\end{tabular}

* Data were reported previously [3].

Phosphomolybdate Assay for Total Antioxidant Capacity (TAC)

The tested compounds transferred one electron to reduce $\mathrm{Mo}^{6+}$ to $\mathrm{Mo}^{5+}$. The amount of the green phosphate $\mathrm{Mo}^{5+}$ complex is proportional with the activity of the compounds; results are presented in Table 4 . The current assay proved an excellent electron-donating capacity for all compounds, with the exception of compound $\mathbf{6 a}$.

Reducing Power (RP) Assay

The reduction of ferricyanide to ferrocyanide by the evaluated compounds yielded the Perls' Prussian blue. The reducing power of the compounds is proportional to the absorbance of the resulted solutions. The results obtained in the RP assay are presented in Table 4 . All the compounds proved noticeable reducing properties, and the best activity was registered for compounds $\mathbf{5 a - b}$ and $\mathbf{8} \mathbf{a}-\mathbf{b}$.

Overall, from all three electron transfer assays and all three antiradical assays it can be observed that, in general, the benzylidene derivatives from series $\mathbf{b}$ presented better electron donating capacity and ability to scavenge the $\mathrm{ABTS}^{+}, \mathrm{DPPH}^{\circ}$, and NO radicals than their corresponding phenylethylidene derivatives from series $\mathbf{a}$.

The very good activity identified for compound $\mathbf{8 b}$ can be structurally explained due to the lack of the methyl group on the azomethine ( $\mathbf{b}$ series) and the presence of the catechol group, in agreement with literature reports that suggest the high activity of this type of compound is due to the internal stabilization of the resulted radicals from the catechol fragment by intramolecular hydrogen bonding [45-47].

\subsubsection{Ferrous and Cupric Ions Chelation Assays}

\section{$\mathrm{Fe}^{2+}$ Chelation Assay}

The chelating potential for the ferrous ions of the new compounds was determined, based on their competition for $\mathrm{Fe}^{2+}$ with ferrozine. The decrease in the absorbance suggested that the ferrous ions were sequestered by the evaluated compounds. The results of 
the assay are shown in Table 5. The chelating potential of compounds of the ferrous ions was negligible compared to that of EDTA- $\mathrm{Na}_{2}$.

Table 5. Results of the ferrous ions chelation capacity evaluation.

\begin{tabular}{|c|c|c|c|c|}
\hline \multirow{2}{*}{ Compound } & \multicolumn{4}{|c|}{ Chelation Capacity (\%) } \\
\hline & $50 \mu \mathrm{g} / \mathrm{mL}$ & $100 \mu \mathrm{g} / \mathrm{mL}$ & $150 \mu \mathrm{g} / \mathrm{mL}$ & $200 \mu \mathrm{g} / \mathrm{mL}$ \\
\hline $5 a$ & $0.27 *$ & $5.06 *$ & 11.17 & 21.69 \\
\hline $5 b$ & 1.18 & 8.95 & 18.42 & 31.33 \\
\hline $6 \mathbf{a}$ & 0.07 & 7.14 & 14.50 & 25.03 \\
\hline $6 b$ & 0.07 & 4.84 & 13.39 & 22.27 \\
\hline $7 \mathbf{a}$ & 0.07 & 1.73 & 2.29 & 3.88 \\
\hline $7 b$ & 0.07 & 3.44 & 9.13 & 16.28 \\
\hline $8 \mathbf{a}$ & 7.73 & 12.28 & 17.60 & 22.64 \\
\hline $8 b$ & 10.74 & 18.15 & 25.06 & 33.38 \\
\hline EDTA-Na $_{2}$ & 20.86 & 57.32 & $>95.00$ & $>95.00$ \\
\hline
\end{tabular}

* Data were reported previously [3].

\section{$\mathrm{Cu}^{2+}$ Chelation Assay}

The potential of chelating cupric ions of the tested compounds was evaluated based on the competition for $\mathrm{Cu}^{2+}$ with murexide, and the results are presented in Table 6 . The chelating activity of compounds for the cupric ions found in the current assay was significant for compounds $5 \mathbf{a}-\mathbf{b}, \mathbf{7} \mathbf{a}$, and $\mathbf{8} \mathbf{a}$, compared to that of EDTA-Na ${ }_{2}$.

Table 6. Results of the cupric ions chelation capacity evaluation.

\begin{tabular}{|c|c|c|c|c|c|}
\hline \multirow{2}{*}{ Compound } & \multicolumn{5}{|c|}{ Chelation Capacity (\%) } \\
\hline & $3.36 \mu \mathrm{g} / \mathrm{mL}$ & $6.72 \mu \mathrm{g} / \mathrm{mL}$ & $10.08 \mu \mathrm{g} / \mathrm{mL}$ & $13.44 \mu \mathrm{g} / \mathrm{mL}$ & $16.80 \mu \mathrm{g} / \mathrm{mL}$ \\
\hline $5 a$ & 10.74 & 14.51 & 20.10 & 28.62 & 33.67 \\
\hline $5 b$ & 11.58 & 15.60 & 22.76 & 28.99 & 34.10 \\
\hline $6 a$ & 6.33 & 10.30 & 13.65 & 15.90 & 18.67 \\
\hline $6 b$ & 3.84 & 6.80 & 10.44 & 14.34 & 17.07 \\
\hline $7 \mathbf{a}$ & 8.76 & 16.70 & 26.63 & 34.35 & 38.88 \\
\hline $7 b$ & 7.23 & 11.41 & 14.46 & 19.40 & 22.72 \\
\hline $8 a$ & 11.13 & 17.02 & 25.14 & 34.16 & 38.91 \\
\hline $8 b$ & 7.34 & 11.97 & 16.62 & 20.30 & 26.71 \\
\hline EDTA-Na 2 & 12.36 & 19.61 & 29.97 & 39.18 & 45.86 \\
\hline
\end{tabular}

\subsection{Electrochemical Behavior of Compounds}

The results obtained from the study of the electrochemical behavior of the synthesized compounds in terms of antioxidant character are presented in Appendix A and suggest that $\mathbf{5 a}, \mathbf{8} a \mathbf{5 b}$, and $\mathbf{8 b}$ may possess this property.

The antioxidant character of the compounds was then tested by four different methods:

- testing the reducing antioxidant power of ferric ions;

- the radical scavenging effect of the novel compounds;

- $\quad$ scavenging of hydrogen peroxide;

- scavenging of 2,2,6,6-tetramethylpiperidinyl-1-oxy (TEMPO).

It was demonstrated that low oxidation potentials values reflect the predisposition of a compound for electron donation, and thus for exhibiting significant antioxidant/ antiradical activity. Moreover, for close oxidation potential values, the antioxidant capacity will be higher for compounds with higher oxidation peak current intensity.

In Figure 2, the cyclic voltammograms (CVs) for each of the compounds considered in this study, compared individually with the voltammogram obtained in the electrolyte $\left(0.1 \mathrm{M} \mathrm{HClO}_{4}\right)$, are presented. Thus, the oxidation/reduction peaks corresponding to the electrochemical transformations suffered by each compound can be observed in the 
potential range considered, in an acidic environment (low $\mathrm{pH}$ ). From Figure 3, where the voltammograms of all eight compounds were presented together, a similarity is observed between $\mathbf{8} \mathbf{a}$ and $\mathbf{8 b}$, and among the other compounds, whereas $\mathbf{5 a}$ and $\mathbf{5 b}$ can be noted as having the highest oxidation signals.

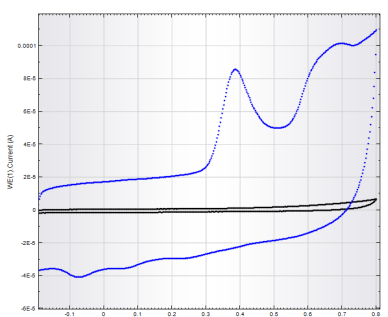

$5 \mathbf{a}$

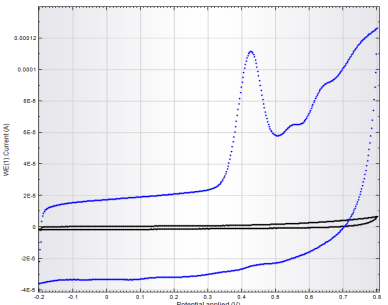

$5 b$

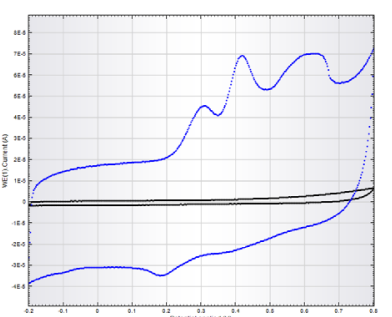

$6 a$

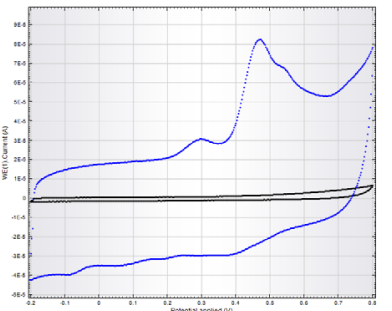

$6 b$

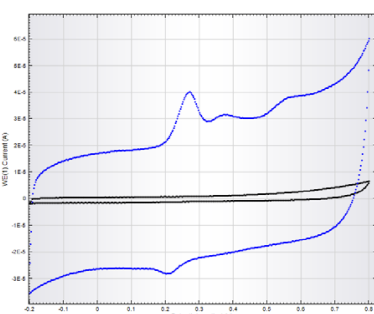

$7 \mathrm{a}$

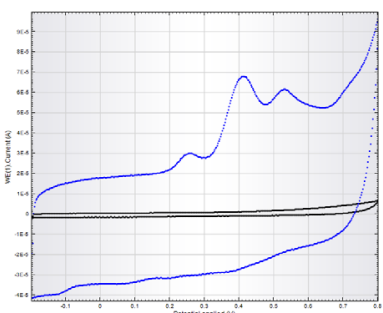

$7 \mathrm{~b}$

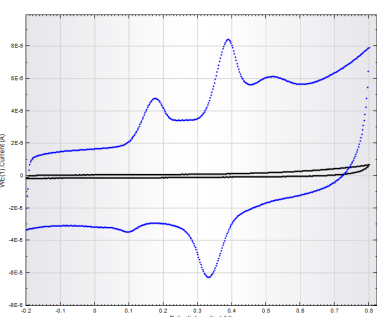

$8 \mathbf{a}$

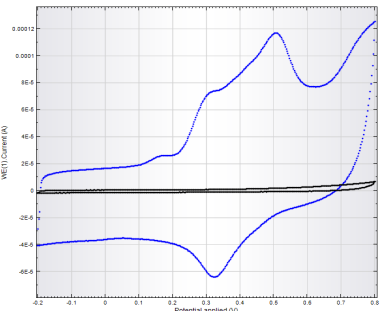

$8 b$

Figure 2. CVs for solutions of the novel synthesized compounds (blue) prepared in $0.1 \mathrm{M} \mathrm{HClO}_{4}$ on graphite-based SPE. Black line: $\mathrm{CV}$ recorded in $0.1 \mathrm{M} \mathrm{HClO}_{4}$.

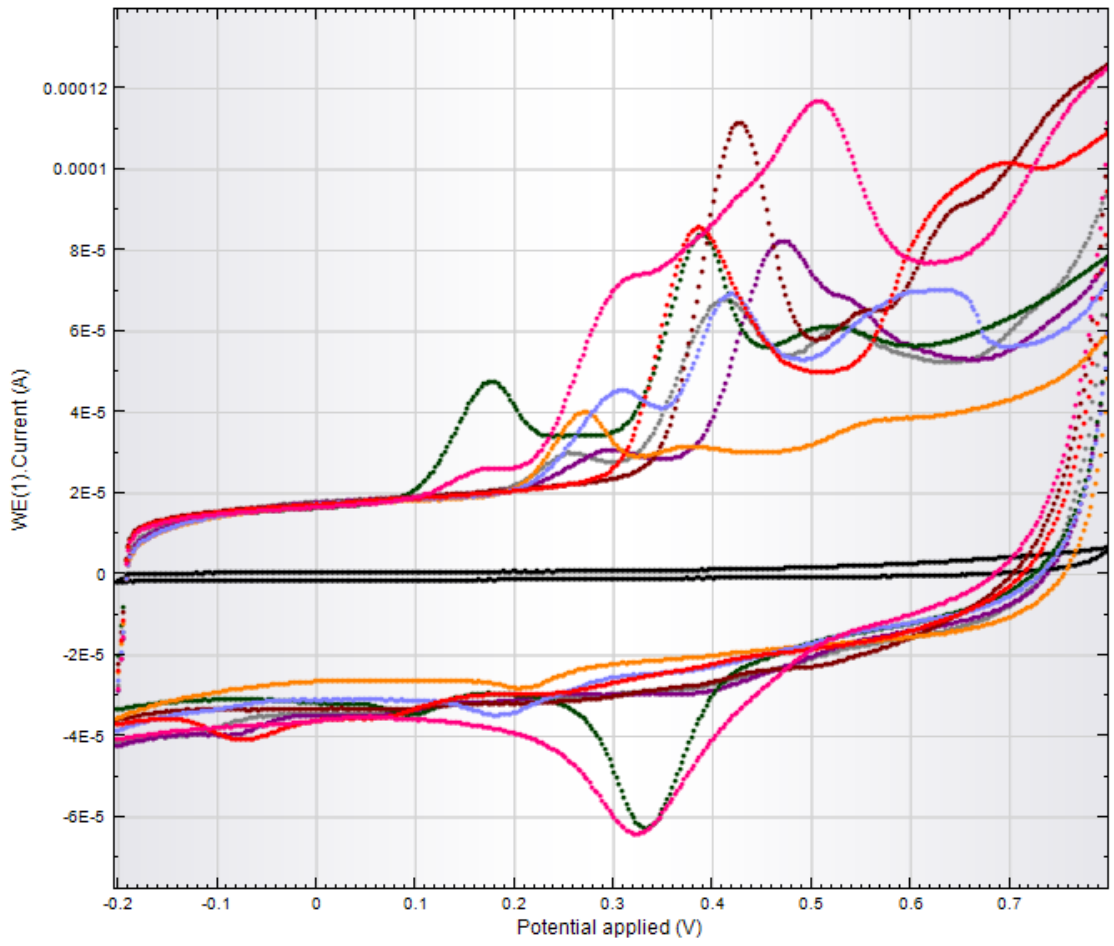

Figure 3. Overlapped CVs for solutions of the novel synthesized compounds: $5 \mathbf{a}$-red; $6 \mathbf{a}-$ light blue; $7 \mathrm{a}$-orange; $8 \mathrm{a}$-green; $5 \mathrm{~b}$-brown; $\mathbf{6 b}$-purple; $7 \mathrm{~b}$-gray; $8 \mathrm{~b}$-pink prepared in $0.1 \mathrm{M} \mathrm{HClO}_{4}$ on graphite-based SPE. Black line: CV recorded in $0.1 \mathrm{M} \mathrm{HClO}_{4}$.

$\mathbf{5 a}$ is represented together with $\mathbf{5 b}$ (Figure $4 \mathbf{a}$ ), and $\mathbf{8 a}$ together with $\mathbf{8 b}$ (Figure $4 \mathbf{b}$ ). 


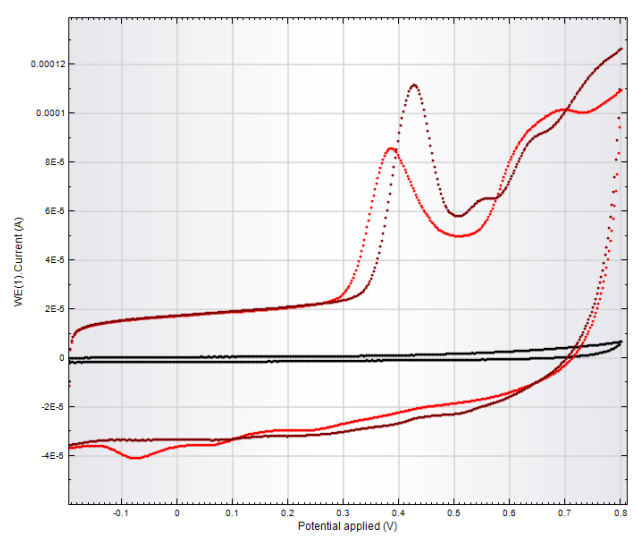

(a)

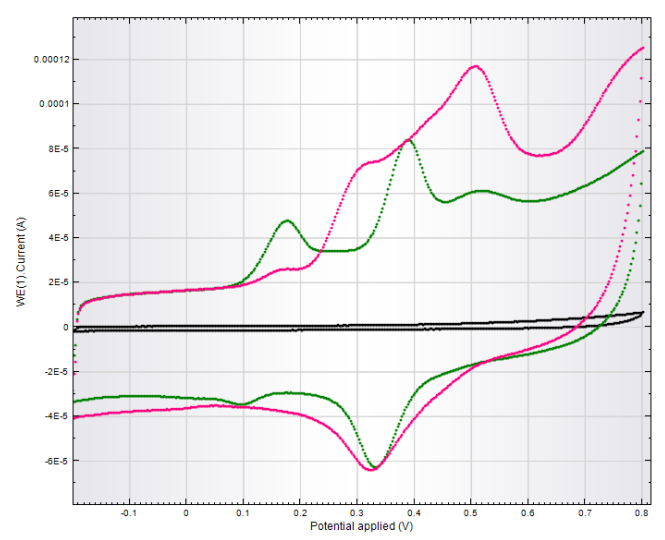

(b)

Figure 4. (a) Comparison between CVs for $\mathbf{5 a}$ (red) and $\mathbf{5 b}$ (brown); (b) comparison between CVs for $\mathbf{8 a}$ (green) and $\mathbf{8 b}$ (pink).

When $\mathbf{5 a}$ and $\mathbf{5 b}$ are compared, it can be observed from Figure $4 \mathrm{a}$ and Table 7 that $\mathbf{5 a}$ has the lowest oxidation potential for the main peak, which suggests that $5 \mathbf{a}$ should have a higher antioxidant capacity than $\mathbf{5 b}$. In the case of $\mathbf{5 b}$, however, a more intense oxidation signal was obtained, so it can be concluded that these two compounds may have similar antioxidant capacity.

Table 7. Comparative presentation of the variation of peak currents and oxidation/reduction potentials for the tested compounds.

\begin{tabular}{|c|c|c|c|c|c|c|c|c|c|c|c|c|}
\hline Compound & $E_{o x}(V)$ & $I_{o x}(\mu \mathrm{A})$ & $E_{o x}(V)$ & $I_{o x}(\mu \mathrm{A})$ & $E_{o x}(V)$ & $I_{o x}(\mu A)$ & $E_{\text {Red }}(V)$ & $I_{\text {Red }}(\mu \mathrm{A})$ & $E_{\text {Red }}(V)$ & $\mathrm{I}_{\mathrm{Red}}(\boldsymbol{\mu} \mathrm{A})$ & $E_{\text {Red }}(V)$ & $I_{\text {Red }}(\mu \mathrm{A})$ \\
\hline $5 a$ & - & - & 0.384 & 50.85 & 0.632 & 19.21 & -0.075 & -6.62 & - & - & 0.256 & -2.17 \\
\hline $5 b$ & - & - & 0.425 & 69.35 & 0.632 & 5.87 & - & - & 0.085 & -0.68 & 0.286 & -2.86 \\
\hline $6 a$ & 0.298 & 10.73 & 0.418 & 22.48 & 0.621 & 15.03 & - & - & 0.181 & -6.84 & 0.379 & -1.19 \\
\hline $6 b$ & 0.296 & 5.28 & 0.467 & 44.99 & - & - & -0.08 & -2.22 & 0.070 & -1.49 & 0.401 & -5.91 \\
\hline $7 a$ & 0.269 & 14.75 & 0.374 & 2.06 & 0.561 & 2.69 & - & - & 0.205 & -4.65 & - & - \\
\hline $7 \mathrm{~b}$ & 0.267 & 13.22 & 0.412 & 15.78 & 0.543 & 6.385 & -1.11 & -0.119 & -1.45 & 0.078 & -2.49 & 0.201 \\
\hline $8 a$ & 0.174 & 21.51 & 0.386 & 37.08 & 0.520 & 4.87 & - & - & 0.101 & -4.79 & 0.335 & -38.91 \\
\hline $8 b$ & 0.166 & 2.19 & 0.508 & 40.99 & - & - & - & - & - & - & 0.325 & -40.37 \\
\hline
\end{tabular}

In the case of compounds $\mathbf{8} \mathbf{a}$ and $\mathbf{8 b}$, there are signals of oxidation with high intensity, but which have reversible behavior, taking into account that they have a signal of intensity reduction close to a suitable reduction potential value (see the signals in Figure $4 \mathrm{~b}$ and the corresponding values of the oxidation/reduction currents and potentials in Table 7). This reversible process occurs only in the case of $\mathbf{8 a}$ and $\mathbf{8 b}$; both compounds are catechol derivatives, and observation is in agreement with previous literature reports [47].

The results obtained by all four methods correlated quite well and confirmed the antioxidant capacity of the four compounds $\mathbf{5 a}-\mathbf{b}$ and $\mathbf{8} \mathbf{a}-\mathbf{b}$, which was in agreement with the results obtained in the in vitro antioxidant and antiradical assays.

\subsection{Theoretical Quantum Calculations}

The frontier molecular orbitals are very important in describing the potential chemical behavior of a compound, and were thus computed. The highest occupied molecular orbital (HOMO) indicates a good electron-donating capacity of the molecule and is linked to the susceptibility of the molecule to be attacked by electrophilic species. Alternatively, the energy of the lowest unoccupied molecular orbital (LUMO) is linked with its electron affinity and with the susceptibility to be attacked by a nucleophilic species. Reports in the literature suggest that the HOMO-LUMO gap may be a parameter that describes the antioxidant activity of the compounds $[4,30]$.

HOMO and LUMO depicted for the compounds $5 \mathbf{a}-\mathbf{b}, \mathbf{6}, \mathbf{a}-\mathbf{b}, \mathbf{7} \mathbf{\mathbf { a } - \mathbf { b }}$ and $\mathbf{8} \mathbf{a}-\mathbf{b}$ are displayed in Table S1 (Supplementary Materials). Due to the substituent present in position 4 of the thiazole (methyl or phenyl), two means of distribution of the HOMO orbital could be identified. In the 4-methyl-thiazole derivatives $\mathbf{5} \mathbf{a}-\mathbf{b}, \mathrm{HOMO}$ was found over the hydrazinyl-thiazole fragment, whereas in the 4-phenyl-thiazole derivatives $6 \mathbf{a}-\mathbf{b}, \mathbf{7} \mathbf{a}-\mathbf{b}$ and 
8a-b, HOMO was found over the thiazolyl-4-phenyl fragment. The position of the HOMO on the specified regions of the molecules indicate that their redox behavior by extraction of electrons will take place due to involvement of that region. In the case of compounds $5 \mathbf{a}-\mathbf{b}$, the increased presence of the HOMO over the hydrazinyl fragment and not over the diphenolic fragment is interesting, suggesting that the antioxidant and antiradical effect can be attributed less to the phenolic fragment and more to the hydrazinyl fragment. Substitution of the thiazole with a phenyl shifted the position of HOMO over the thiazolyl-4-phenyl fragment, reducing the influence of the hydrazine in the redox behavior of the compounds $(6 \mathbf{a}-\mathbf{b}, 7 \mathbf{a}-\mathbf{b}$, and $\mathbf{8 a}-\mathbf{b})$. Therefore, the substitution with an aromatic nucleus in position 4 of the thiazole ring was essential for the redox behavior of the compounds that have it in their structure (6a-b, 7a-b, and $8 a-b)$.

Substitution of the azomethine carbon atom with methyl (a series of compounds) or hydrogen ( $\mathbf{b}$ series of compounds) led to tiny changes in the positioning of HOMO between the two series of compounds. From a numerical point of view, in the case of $\mathrm{HOMO}$, the difference between series $\mathbf{a}$ and series $\mathbf{b}$ of compounds was between 0.04 and $0.06 \mathrm{eV}$ (Table 8), and larger differences appeared in the case of LUMO, up to $0.25 \mathrm{eV}$ (5a vs. 5b).

Table 8. Results of the quantum calculations.

\begin{tabular}{cccc}
\hline Compound & HOMO (eV) & LUMO $(\mathbf{e V})$ & HOMO-LUMO Gap (eV) \\
\hline $\mathbf{5 a}$ & -5.63 & -0.95 & 4.68 \\
$\mathbf{5 b}$ & -5.69 & -1.20 & 4.49 \\
$\mathbf{6 a}$ & -5.52 & -1.06 & 4.46 \\
$\mathbf{6 b}$ & -5.58 & -1.28 & 4.30 \\
$\mathbf{7 a}$ & -5.41 & -1.22 & 4.19 \\
$\mathbf{7 b}$ & -5.47 & -1.28 & 4.19 \\
$\mathbf{8 a}$ & -5.18 & -1.06 & 4.12 \\
$\mathbf{8 b}$ & -5.22 & -1.30 & 3.92 \\
\hline
\end{tabular}

Interestingly, on the 2,4-diphenolic fragment $\mathrm{HOMO}$ was little present (5a-b) or even absent (6a-b, 7a-b and $\mathbf{8 a - b})$, indicating that this fragment is not the one that causes the main antioxidant and antiradical activity in the case of these compounds.

It cannot be considered that the 2,4-diphenolic fragment is inert and does not contribute to the activity of the molecules, but that it intervenes in a lesser extent than does the hydrazine function or other substituents present on the aromatic nucleus from position 4 of the thiazole heterocycle. This can be explained by two arguments: the $\mathrm{OH}$ groups are not adjacent (the catechol has a much higher antioxidant activity than non-adjacent ones) and the benzene ring is found near the electron withdrawing azomethine group, reducing the antioxidant potential of the phenols.

As described above, because the HOMO distribution was not similar in the case of the synthesized compounds, this interpretation was made according to this distribution. The highest HOMO-LUMO gap values were identified for compounds $\mathbf{5 a}$ and $\mathbf{5 b}$ (4.68 and $4.49 \mathrm{eV}$, respectively). Then, in the case of compounds having an aromatic nucleus in position 4 of the thiazole nucleus, this value decreased, starting from $4.46 \mathrm{eV}(6 \mathbf{a}), 4.30 \mathrm{eV}$ (6b), $4.19 \mathrm{eV}$ (7a and $\mathbf{7 b}), 4.12 \mathrm{eV}(\mathbf{8 a})$, and $3.92 \mathrm{eV}(\mathbf{8 b})$. We can see that the catechol substitution of the aromatic ring at position 4 of the thiazole is able to improve the activity of these compounds and the substitution of the azomethine carbon atom with hydrogen is similar to that of methyl.

In order to evaluate how the hydrogen can be released from the present molecules, the bond dissociation enthalpy (BDE) of O-H, N-H, and $\mathrm{C}-\mathrm{H}$ bonds was computed from the possible molecular sites to identify which is the most susceptible hydrogen atom to be released. Obviously, the bond dissociation energies of hydrogen atoms bound to methyl groups or benzene rings were not calculated. Molecular sites likely to release hydrogen atoms were noted from $\mathrm{H}_{1}$ to $\mathrm{H}_{7}$, according to the general structure depicted in Figure 5 . 
The computed X-H BDE (where $\mathrm{X}=\mathrm{N} / \mathrm{C} / \mathrm{O}$ ) from the $\mathrm{H}_{1}-\mathrm{H}_{7}$ available sites in the studied compounds are presented in Table 9.

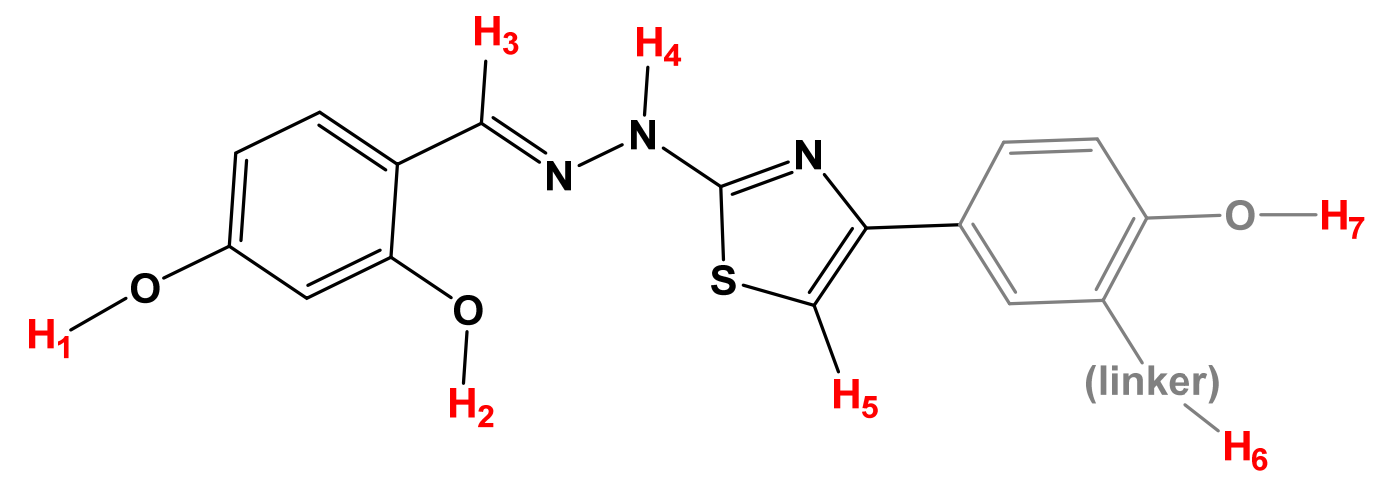

Figure 5. General structure of the compounds and the possible sites which can release hydrogen atoms to neutralize radicals numbered $\mathrm{H}_{1}-\mathrm{H}_{7}$.

Table 9. The computed BDE for the hydrogen atoms from the studied compounds $(\mathrm{kcal} / \mathrm{mol})$.

\begin{tabular}{cccccccc}
\hline Compound & $\mathbf{H}_{\mathbf{1}}$ & $\mathbf{H}_{\mathbf{2}}$ & $\mathbf{H}_{\mathbf{3}}$ & $\mathbf{H}_{\mathbf{4}}$ & $\mathbf{H}_{\mathbf{5}}$ & $\mathbf{H}_{\mathbf{6}}$ & $\mathbf{H}_{\mathbf{7}}$ \\
\hline $\mathbf{5 a}$ & 81.1 & $\mathbf{7 0 . 2}$ & $\mathrm{N} / \mathrm{A}$ & $\mathbf{6 7 . 3}$ & 116.8 & $\mathrm{~N} / \mathrm{A}$ & $\mathrm{N} / \mathrm{A}$ \\
$\mathbf{5 b}$ & 80.8 & $\mathbf{6 5 . 9}$ & 99.0 & $\mathbf{6 3 . 3}$ & 116.9 & $\mathrm{~N} / \mathrm{A}$ & $\mathrm{N} / \mathrm{A}$ \\
$\mathbf{6 a}$ & 81.3 & $\mathbf{7 0 . 2}$ & $\mathrm{N} / \mathrm{A}$ & $\mathbf{6 7 . 3}$ & 115.1 & $\mathrm{~N} / \mathrm{A}$ & N/A \\
$\mathbf{6 b}$ & 81.0 & $\mathbf{6 5 . 8}$ & 99.0 & $\mathbf{6 3 . 1}$ & 116.1 & $\mathrm{~N} / \mathrm{A}$ & N/A \\
$\mathbf{7 a}$ & 81.4 & $\mathbf{6 9 . 4}$ & $\mathrm{N} / \mathrm{A}$ & $\mathbf{6 6 . 6}$ & 114.4 & 103.5 & 79.2 \\
$\mathbf{7 b}$ & 81.0 & $\mathbf{6 6 . 1}$ & 99.0 & $\mathbf{6 3 . 4}$ & 115.2 & 96.9 & 81.4 \\
$\mathbf{8 a}$ & 81.2 & $\mathbf{6 9 . 4}$ & N/A & $\mathbf{6 6 . 5}$ & 114.0 & $\mathbf{6 9 . 2}$ & 75.8 \\
$\mathbf{8 b}$ & 79.5 & $\mathbf{6 5 . 2}$ & 99.0 & $\mathbf{6 2 . 3}$ & 114.7 & $\mathbf{6 9 . 3}$ & 76.0 \\
\hline N/A: not applicable. The lowest BDE values are marked in bold.
\end{tabular}

The most available site for releasing hydrogen atoms from our compounds is the hydrazine unit, numbered with $\mathrm{H}_{4}$ in the general structure, and the BDE computed for this site ranging between $62.3 \mathrm{kcal} / \mathrm{mol}(\mathbf{8 b})$ to $67.3 \mathrm{kcal} / \mathrm{mol}(\mathbf{5 a}, \mathbf{6 a})$. The second site that can release hydrogen atoms for the manifestation of the antiradical effect is represented by $\mathrm{H}_{2}$, which has slightly higher BDE values than $\mathrm{H}_{4}$, ranging between $65.2 \mathrm{kcal} / \mathrm{mol}(8 \mathbf{b})$ and $70.2 \mathrm{kcal} / \mathrm{mol}(\mathbf{5 a}, \mathbf{6 a})$. Analyzing in terms of value and order of $\mathrm{BDE}$ for $\mathrm{H}_{2}$ and $\mathrm{H}_{4}$, it can be seen that the two energies follow the same trend in the present series of compounds.

The analysis of the most stable conformations or the radical species at the $\mathrm{H}_{4}$ site resulted from quantum calculations indicated the formation of a hydrogen bond between the phenolic hydroxyl group from the ortho $\left(\mathrm{H}_{2}\right)$ position and the azomethine nitrogen atom. This represents a form of intramolecular stabilization with the formation of a pseudobicyclic system, with high stability that favors extended conjugation, the stability of the resulting radical, and a better antiradical activity of the parent compound. Therefore, the presence of the $\mathrm{OH}$ group in the ortho position $\left(\mathrm{H}_{2}\right.$ site) has a dual role: an antiradical role, known for phenolic compounds, but also stabilizing the hydrazone group to promote its antiradical activity and stabilize the resulting radical species. This observation is in agreement with previous literature reports [46,47].

The lowest BDEs are found in the $\mathbf{b}$ series of compounds, compared to analogous compounds in the a series; therefore, we consider that the presence of the methyl residue on the methylene carbon atom is unfavorable to the antiradical action. Because the $\mathrm{H}_{1}$ and $\mathrm{H}_{4}$ sites are spatially close to each other, the presence of the methyl residue can interfere with the internal stabilization of the radical resulting from the loss of the hydrogen atom from one of the hydrazine $\left(\mathrm{H}_{4}\right)$ sites, probably by making the $\mathrm{C}=\mathrm{N}$ double bond mor rigid, making it more difficult to bring the $\mathrm{OH}$ group in the ortho $\left(\mathrm{H}_{2}\right.$ site $)$ closer to the hydrazone nitrogen atom to form the intramolecular hydrogen bond to stabilize the resulting radical. 
Interesting, the $\mathrm{H}_{1}$ site corresponding to the phenolic $\mathrm{OH}$ group from para of both benzene rings is not considered to have significant potential to release hydrogen atoms, having slightly higher BDE values $(75.8-81.4 \mathrm{kcal} / \mathrm{mol})$. Although it does not act as a direct antiradical by releasing hydrogen atoms, it probably helps to stabilize the radicals resulting from the radicalization of $\mathrm{H}_{2}$ and $\mathrm{H}_{4}$ functions by its electron donor effect.

In the case of the catechol group from compounds $\mathbf{8} \mathbf{a}-\mathbf{b}$, the phenolic $\mathrm{OH}$ group from meta $\left(\mathrm{H}_{6}\right)$ has a BDE lower than that from the para position $\left(\mathrm{H}_{7}\right)$, and the value is close to those from $\mathrm{H}_{2}$ and $\mathrm{H}_{4}$. Therefore, in the case of compounds 8a-b it can be considered that they have multiple groups within the same molecule that manifest the action, resulting in a compound with a very high antiradical activity; these fall into the category of hybrid molecules.

From the antiradical point of view, the methylene $\mathrm{H}_{3}$ site (b series of compounds), the thiazole $\mathrm{H}_{5}$ site (all compounds of the present paper), and the amide $\mathrm{H}_{6}$ site (compounds $7 \mathbf{a}-\mathbf{b}$ ) can be considered to be inert in terms of hydrogen atoms release.

\subsection{Antimicrobial Activity Evaluation}

The antimicrobial activity of the final compounds, against seven aerobic microbial strains (S. aureus ATCC 25923, S. pyogenes ATCC 19615, P. aeruginosa ATCC 27853, S. enterica ISM 83/37, S. typhimurium ATCC 14028, E. coli ATCC 8739, E. coli ATCC 25922), and a fungal strain (C. albicans ATCC 102310), was determined using a modified microdilution technique.

The results of the antimicrobial activity evaluation of the compounds, in comparison to norfloxacin and chloramphenicol used as standard antibiotics and fluconazole used as reference antifungal, are depicted in Table 10. Values over $100 \mu \mathrm{g} / \mathrm{mL}$ are replaced with "-“ and the compound was considered inactive on the respective microbial strain.

Table 10. Minimum inhibitory concentrations (MIC $(\mu \mathrm{g} / \mathrm{mL})$ ) of the synthesized compounds.

\begin{tabular}{|c|c|c|c|c|c|c|c|c|}
\hline Compound & $\begin{array}{c}\text { S. aureus } \\
\text { ATCC } 25923\end{array}$ & $\begin{array}{l}\text { S. pyogenes } \\
\text { ATCC } 19615\end{array}$ & $\begin{array}{l}\text { P. aeruginosa } \\
\text { ATCC } 27853\end{array}$ & $\begin{array}{l}\text { S. enterica } \\
\text { ISM } 83 / 37\end{array}$ & $\begin{array}{l}\text { S. typhimurium } \\
\text { ATCC } 14028\end{array}$ & $\begin{array}{c}\text { E. coli } \\
\text { ATCC } 8739\end{array}$ & $\begin{array}{c}\text { E. coli } \\
\text { ATCC } 25922\end{array}$ & $\begin{array}{c}\text { C. albicans } \\
\text { ATCC } 102310\end{array}$ \\
\hline $5 a$ & - & - & 31.2 & - & - & - & - & - \\
\hline $5 b$ & - & - & 31.2 & - & - & - & - & - \\
\hline $6 a$ & - & - & 31.2 & - & - & - & - & - \\
\hline $6 b$ & - & - & - & - & - & - & - & 62.5 \\
\hline $7 a$ & 62.4 & 31.2 & 3.9 & - & - & - & - & - \\
\hline $7 \mathrm{~b}$ & - & - & 15.6 & - & - & - & - & - \\
\hline $8 a$ & - & - & 7.8 & - & - & - & - & - \\
\hline $8 b$ & - & - & 31.2 & - & - & - & - & - \\
\hline Norfloxacin & 0.48 & $<0.48$ & 7.8 & $<0.48$ & $<0.48$ & $<0.48$ & 7.8 & NT \\
\hline Chloramphenicol & 7.8 & 3.9 & 0.48 & 3.9 & $<0.48$ & 7.8 & 3.9 & NT \\
\hline Fluconazole & NT & NT & NT & NT & NT & NT & NT & 31.2 \\
\hline
\end{tabular}

NT: not tested. The best MIC values are marked in bold.

The synthesized compounds presented a modest antifungal activity, and compound $\mathbf{6 b}$ was the only one active against the strain of C. albicans used for testing. Regarding the antibacterial activity, it can be observed that against the Gram-positive S. aureus and S. pyogenes bacterial strains, only compound 7a presented inhibitory properties. With the exception of compound $\mathbf{6 b}$, all the other compounds were active against the Gram-negative P. aeruginosa strain, compounds $7 \mathbf{a}$ and $\mathbf{8 a}$ having the best antibacterial properties, presenting lower or equal MIC values to that of norfloxacin, which was used as a reference. These two compounds ( $7 \mathbf{a}$ and $\mathbf{8 a}$ ) also presented good cupric ions chelating activity, which may suggest a potential mechanism of antibacterial action, by subtracting transitional metal ions essential for bacterial metabolism. However, this needs further investigation.

\subsection{Cytotoxicity Studies}

\subsubsection{Cytotoxicity Determination}

The $\mathrm{IC}_{50}$ values for the compounds against $\mathrm{HaCaT}$ cell lines were determined using the MTT viability test (Table 11). According to the $\mathrm{IC}_{50}$ values determined, the ranking of 
the compounds is as follows: $\mathbf{6 b}>\mathbf{8 b}>\mathbf{7 a}>\mathbf{5 a}>\mathbf{7 b}>\mathbf{8 a}>\mathbf{5 b}>\mathbf{6 a}$, where $\mathbf{6 b}$ is the most cytotoxic compound ( $\left.\mathrm{IC}_{50}<0.50 \mu \mathrm{g} / \mathrm{mL}\right)$ and $6 \mathrm{a}$ is the least cytotoxic $\left(\mathrm{IC}_{50}=126.76 \mu \mathrm{g} / \mathrm{mL}\right)$.

Table 11. The $\mathrm{IC}_{50}$ values of the compounds against HaCaT cells determined through the MTT method.

\begin{tabular}{ccc}
\hline Compound & $\mathrm{IC}_{\mathbf{5 0}}(\boldsymbol{\mu g} / \mathbf{m L})$ & $\mathrm{IC}_{\mathbf{5 0}}(\mathbf{n M})$ \\
\hline $\mathbf{5 a}$ & 30.70 & 102.41 \\
$\mathbf{5 b}$ & 50.34 & 176.17 \\
$\mathbf{6 a}$ & 126.76 & 311.99 \\
$\mathbf{6 b}$ & $<0.50$ & $<1.27$ \\
$\mathbf{7 a}$ & 35.13 & 75.50 \\
$\mathbf{7 b}$ & 42.36 & 93.86 \\
$\mathbf{8 a}$ & 44.59 & 113.22 \\
$\mathbf{8 b}$ & 8.54 & 22.48 \\
Ascorbic acid & 22.77 & 129.29 \\
\hline
\end{tabular}

\subsubsection{HaCaT Cells' Integrity}

The acridine orange fluorescent signals of the cells were correlated with the $\mathrm{IC}_{50}$ values which described 7a (Figure 6f) as most cytotoxic and 6a (Figure 6d) as the least cytotoxic compound from the three selected compounds $\mathbf{6 a}, \mathbf{7 a}$, and $\mathbf{8 a}$. The red signals are specific for necroptotic cells when the dye is bound to acidic diffuse structures (e.g., lysed lysosomes) and suggest the cytotoxic microenvironment. In contrast, green fluorescence is for DNA and for viable nucleated cells. As compared to the AA (Figure 6b) and $\mathrm{H}_{2} \mathrm{O}_{2}$ (hydrogen peroxide) (Figure 6c) effects, 6a action (Figure 6d) was similar to the AA effects when the nucleus was regular shaped, with green fluorescence without chromatin fragments. By contrast, the 8a effects on HaCaT cells induced nuclear fragmentation (Figure 6e) and nucleus/cytoplasm disproportion, and suggested that the cells were orientated to necroptosis. The cellular action of the compound 7a (Figure 6f) induced a necroptotic aspect of the cells, uniformized red signals, and acidic cytoplasm, which suggests cellular toxic events induced by 7a. Interestingly, the LDH (Figure 6g) and CAT (Figure 6h) activities were decreased after the treatments with the tested compounds as compared to the $\mathrm{H}_{2} \mathrm{O}_{2}$ effects. The decreased activity of the LDH and CAT after the tested compounds treatment was explained as the bidirectional action of these compounds on the HaCaT cells. The compounds induced necroptotic status but, at the same time, the molecules protected the plasma membrane against oxidative stress attack and lysosome diffusion, as depicted in Figure $6 \mathrm{~d}-\mathrm{f}$. In comparison to the AA action, these compounds acted in a slight cellular detrimental manner (increasing tendency for LDH and CAT, Figure 6g-h). Nevertheless, in oxidative conditions, the compounds act as antioxidants (6a) but with important cytotoxic effects (7a).

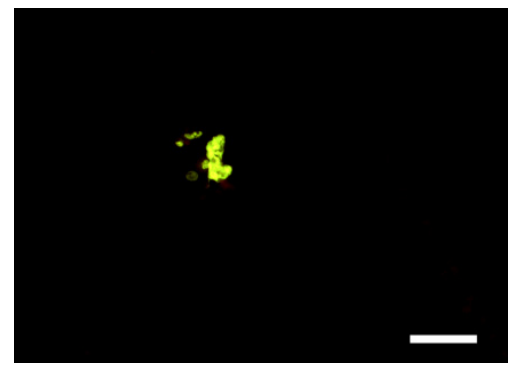

(a)

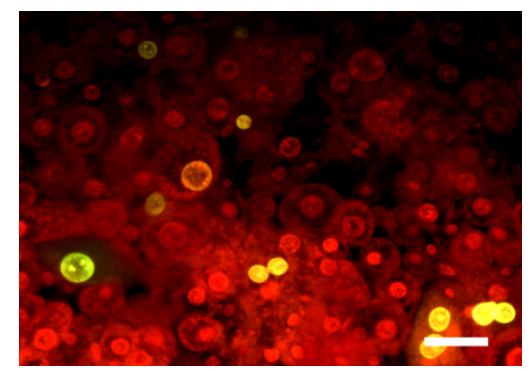

(b)

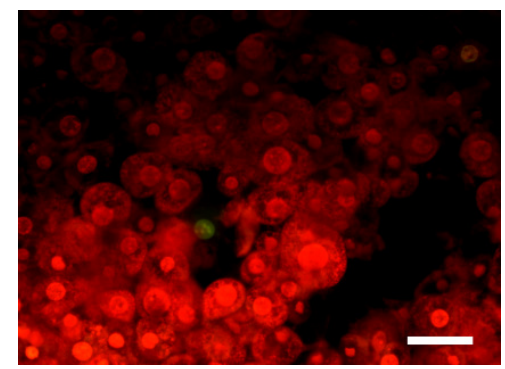

(c)

Figure 6. Cont. 


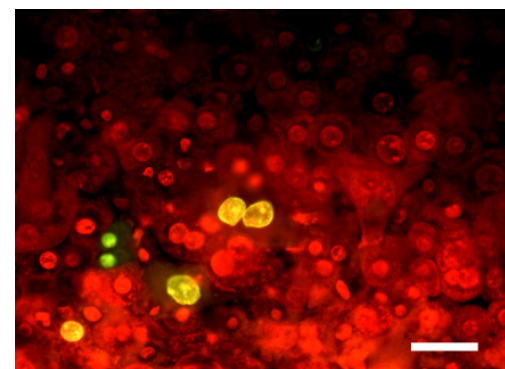

(d)

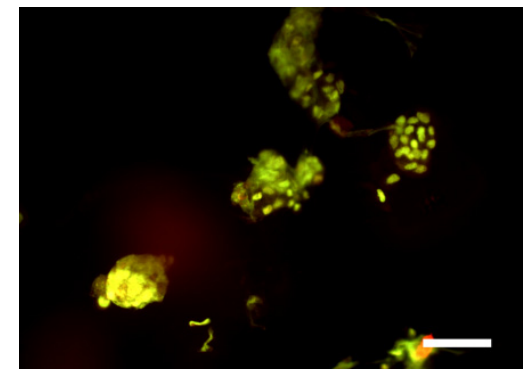

(e)

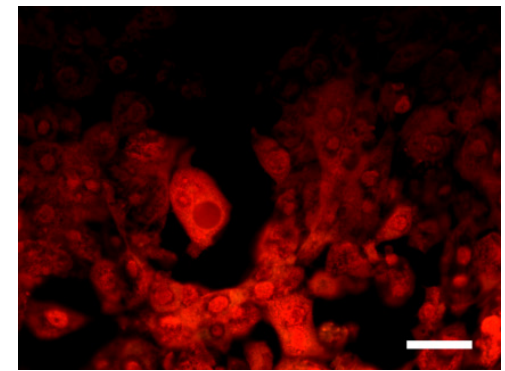

(f)

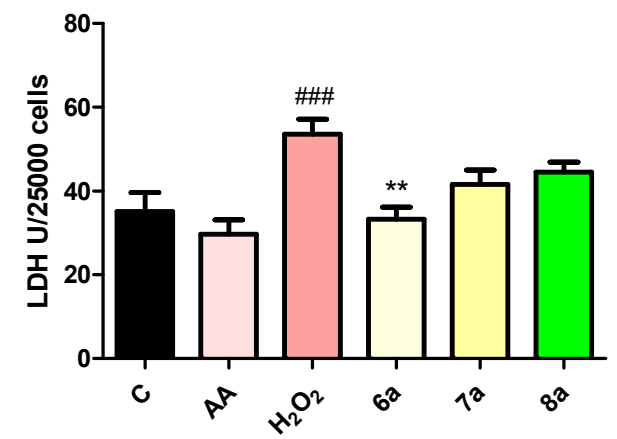

$(\mathrm{g})$

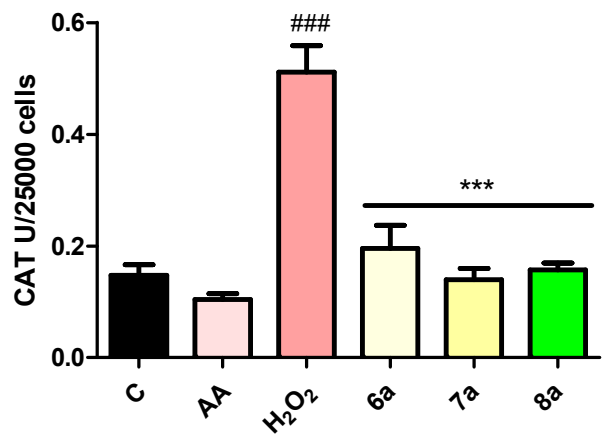

(h)

Figure 6. Acridine-orange staining $(\mathbf{a}-\mathbf{f})$ and enzymes assay $(\mathrm{g}-\mathrm{h})$ of the control and treated HaCaT cells: (a) control; (b) ascorbic acid (AA); (c) hydrogen peroxide $\left(\mathrm{H}_{2} \mathrm{O}_{2}\right)$; (d) 6a; (e) 8a; (f) 7a. Scale bar $=20 \mu \mathrm{m}, \times 400$. Enzymes assays are presented for lactate dehydrogenase (LDH) (g) and catalase (CAT) (h) in U/no. of the cells. $p<0.05$ was considered statistically significant. The significance was marked with ${ }^{* *}$ for $p<0.01$, *** for $p<0.001$ (compared to $\mathrm{H}_{2} \mathrm{O}_{2}$ effects) and ${ }^{\# \#}$ for $p<0.001$ for the comparison with the AA effects.

\subsection{Molecular Properties with Influence on the Pharmacokinetics of Compounds}

In order to obtain preliminary information about the pharmacokinetics of the compounds, some molecular parameters were computed and are presented in Table 12. Compounds $5 \mathbf{a}-\mathbf{b}$ and $\mathbf{6} \mathbf{a}-\mathbf{b}$ have a topological polar surface area (TPSA) equal to $105.98 \AA^{2}$, below the limit of $140 \AA^{2}$ required to be considered as having a good absorption after oral administration. Compounds $\mathbf{8} \mathbf{a}-\mathbf{b}$, slightly exceed the limit, having a TPSA value of $146.44 \AA^{2}$ and have an oral absorption of $58.48 \%$, whereas compounds $7 \mathbf{a}-\mathbf{b}$ have the highest TPSA value in the present series, equal to $169.3 \AA^{2}$, and a consecutive gastrointestinal absorption (GIA) equal to $50.59 \%$, the smallest in this series of compounds.

Table 12. Molecular parameters of the compounds without hydro acid (CwHA) of the final salefied compounds with strong influence on the preliminary steps of pharmacokinetics of compounds.

\begin{tabular}{|c|c|c|c|c|c|c|c|c|c|c|}
\hline CwHA & MW & HBA & HBD & TPSA $\left(\AA^{2}\right)$ & GIA (\%) & iLOGP & XLOGP3 & WLOGP & MLOGP & $\mathrm{pKa}$ \\
\hline $5 a$ & 263.32 & 4 & 3 & 105.98 & 72.44 & 2.19 & 2.81 & 2.51 & 0.91 & 8.0 \\
\hline $5 b$ & 249.29 & 4 & 3 & 105.98 & 72.44 & 1.33 & 2.59 & 2.12 & 0.63 & 8.1 \\
\hline $6 a$ & 325.38 & 4 & 3 & 105.98 & 72.44 & 2.37 & 4.08 & 3.87 & 1.96 & 7.9 \\
\hline $6 b$ & 311.36 & 4 & 3 & 105.98 & 72.44 & 1.74 & 3.85 & 3.48 & 1.72 & 8.1 \\
\hline $7 a$ & 384.41 & 6 & 5 & 169.30 & 50.59 & 1.81 & 3.15 & 2.67 & 0.67 & 6.5 \\
\hline $7 \mathbf{b}$ & 370.38 & 6 & 5 & 169.30 & 50.59 & 1.98 & 2.93 & 2.28 & 0.43 & 6.5 \\
\hline $8 a$ & 357.38 & 6 & 5 & 146.44 & 58.48 & 2.08 & 3.37 & 3.28 & 0.88 & 8.0 \\
\hline $8 b$ & 343.36 & 6 & 5 & 146.44 & 58.48 & 1.18 & 3.14 & 2.89 & 0.64 & 7.9 \\
\hline AA & 176.12 & 6 & 4 & 107.22 & 72.01 & -0.05 & -1.64 & -1.41 & -2.60 & 4.2 \\
\hline
\end{tabular}

CwHA: compounds without hydro acid, MW: molecular weight, HBA: hydrogen bond acceptors, HBD: hydrogen bond donors, TPSA: topological polar surface area, GIA: gastrointestinal absorption, iLOGP: implicit octanol-water partition coefficient [48], XLOGP3: computational octanol-water partition coefficient calculated according to Cheng et al. [49], WLOGP: $\log P$ coefficient calculated by Wildman and Crippen method [50], MLOGP: Moriguchi octanol-water partition coefficient [51]. 
Octanol-water partition coefficients were computed using multiple algorithms available in the Swiss ADME web tool. It can be seen (Table 12) that the compounds of series a have a higher lipophilicity than their structural analogues of series $\mathbf{b}$, expressed by higher values of $\log P$. Overall, the compounds did not violate any of Lipinski's rules.

The $\mathrm{pKa}$ of the most acidic group of each compound is presented in Table 12. Although the studied compounds have several phenolic groups, the acidic character of these compounds (pKa ranging between 6.5 and 8.1) is lower than that of ascorbic acid ( $\mathrm{pKa}=4.2$ ). This finding is important, especially linked with the results of the cytotoxicity study, because the acidic properties of the ascorbic acid can lead to damaging the cells, whereas in our compounds this effect is reduced due to the lower acidity of the chemical groups.

\section{Conclusions}

The in vitro antiradical and antioxidant evaluation revealed that all synthesized compounds presented significant activity. The most active compounds of these series were compounds $\mathbf{5 a - b}$ and $\mathbf{8} \mathbf{a}-\mathbf{b}$, and these findings are in accordance with the studied thermodynamic and electrochemical properties. The toxicity screening identified that the phenylethylidene derivatives (series a) were better tolerated than the benzylidene derivatives (series b). Among the most active compounds in terms of antioxidant potential, compound 8a emerged, which also presented a good tolerability and a notable anti-Pseudomonas aeruginosa ATCC 27853 activity, similar to that of norfloxacin used as a reference antibiotic. Even though compound $7 \mathbf{a}$ displayed the best antibacterial activity in our series, and good antioxidant and antiradical properties, unfortunately it exhibited high toxicity. Although the ferric ions chelation activity of the compounds was low, the cupric ions chelation activity was noteworthy for compounds $5 \mathbf{a}-\mathbf{b}, 7 \mathbf{a}$, and $\mathbf{8 a}$.

Supplementary Materials: The following are available online at https:/ /www.mdpi.com/article / 10.3390/antiox10111707/s1, Table S1: HOMO and LUMO depicted for the compounds 5a-b, 6a-b, 7a-b and $\mathbf{8 a - b}$, Figure S1: FTIR spectrum of compound $\mathbf{5 b}$, Figure S2: MS spectrum of compound $5 \mathbf{b}$, Figure S3: ${ }^{1} \mathrm{H}-\mathrm{NMR}$ spectrum of compound $5 \mathbf{b}$, Figure S4: ${ }^{13} \mathrm{C}-\mathrm{NMR}$ spectrum of compound 5b, Figure S5: FTIR spectrum of compound 6a, Figure S6: MS spectrum of compound 6a, Figure S7: ${ }^{1} \mathrm{H}-\mathrm{NMR}$ spectrum of compound 6a, Figure S8: ${ }^{13} \mathrm{C}-\mathrm{NMR}$ spectrum of compound 6a, Figure S9. FTIR spectrum of compound $\mathbf{6 b}$, Figure S10: MS spectrum of compound $6 \mathbf{b}$, Figure S11: ${ }^{1} \mathrm{H}-\mathrm{NMR}$ spectrum of compound $\mathbf{6 b}$, Figure S12: ${ }^{13} \mathrm{C}-\mathrm{NMR}$ spectrum of compound $\mathbf{6 b}$, Figure S13: FTIR spectrum of compound 7a, Figure S14: MS spectrum of compound 7a, Figure S15: ${ }^{1} \mathrm{H}-\mathrm{NMR}$ spectrum of compound 7a, Figure S16: ${ }^{13} \mathrm{C}-\mathrm{NMR}$ spectrum of compound $7 \mathbf{a}$, Figure S17: FTIR spectrum of compound $\mathbf{7 b}$, Figure S18: MS spectrum of compound $7 \mathbf{b}$, Figure S19: ${ }^{1} \mathrm{H}-\mathrm{NMR}$ spectrum of compound $7 \mathbf{b}$, Figure S20: ${ }^{13}$ C-NMR spectrum of compound $7 \mathbf{b}$, Figure S21: FTIR spectrum of compound 8a, Figure S22: MS spectrum of compound 8a, Figure S23: ${ }^{1} \mathrm{H}-\mathrm{NMR}$ spectrum of compound 8a, Figure S24: ${ }^{13} \mathrm{C}-\mathrm{NMR}$ spectrum of compound 8a, Figure S25: FTIR spectrum of compound $\mathbf{8 b}$, Figure S26: MS spectrum of compound $\mathbf{8 b}$, Figure S27: ${ }^{1} \mathrm{H}-\mathrm{NMR}$ spectrum of compound $\mathbf{8 b}$, Figure S28: ${ }^{13} \mathrm{C}-\mathrm{NMR}$ spectrum of compound $\mathbf{8 b}$.

Author Contributions: Conceptualization, G.M., A.S., A.H.F., I.O. and O.O.; methodology, G.M., A.H.F., D.C.V., G.B., M.T., I.S., C.C., A.C., B.D., V.-A.T. and L.V.; validation, A.S. and O.O.; formal analysis, G.M., M.T., I.Ș., A.C., B.D. and V.-A.T.; investigation, G.M., M.T., I.S., A.C., B.D., V.-A.T., A.P., L.V., D.C.V. and G.B.; resources, G.M., D.C.V., G.B., M.T., I.S., C.C., A.P., A.C. and V.-A.T.; data curation, G.M., D.C.V., G.B., M.T., I.S., C.C., A.P., A.C. and V.-A.T.; writing—original draft preparation, G.M., D.C.V., M.T., A.C. and V.-A.T.; writing-review and editing, G.M. and A.S.; visualization, G.M., A.S., D.C.V., M.T. and V.-A.T.; supervision, G.M. and O.O.; project administration, G.M. and O.O.; funding acquisition, G.M. and A.P. All authors have read and agreed to the published version of the manuscript.

Funding: This paper was published under the frame of European Social Found, Human Capital Operational Programme 2014-2020, project no. POCU/380/6/13/125171. This research was funded by "Iuliu Haţieganu" University of Medicine and Pharmacy, Cluj-Napoca, Romania, for PCD 7690/68/15.04.2016 and the Romanian Ministry of Research and Innovation, through the Core Program for PN 19350201. 
Institutional Review Board Statement: Not applicable.

Informed Consent Statement: Not applicable.

Data Availability Statement: Data supporting reported results can be found within the article, Appendix A or Supplementary Materials.

Conflicts of Interest: The authors declare no conflict of interest.

\section{Appendix A}

The electrochemical evaluation of the antioxidant capacity of compounds $\mathbf{5 a - b}, \mathbf{6} \mathbf{a}-\mathbf{b}$, $\mathbf{7 a - b}$, and $\mathbf{8} \mathbf{a}-\mathbf{b}$ by comparison with control antioxidants is presented in Appendix A.

Electrochemical evaluation of the antioxidant capacity of compounds 5a-b, 6a-b, $7 a-b$ and $8 a-b$ by comparison with control antioxidants

\section{Ferric ions $\left(\mathrm{Fe}^{3+}\right)$ reducing antioxidant power}

A common method used for in vitro determination of reducing capacity of compounds is $\mathrm{Fe}^{3+}$ reducing ability. The reducing power of a compound reflects the electron donating capacity and this may be associated with antioxidant activity.

This method is based on the evaluation of the influence of the compound measured by the direct reduction of $\mathrm{Fe}\left[(\mathrm{CN})_{6}\right]^{3-}$ to $\mathrm{Fe}\left[(\mathrm{CN})_{6}\right]^{2-}$. This assay is based on the reduction of $\mathrm{Fe}^{3+}$ to $\mathrm{Fe}^{2+}$ due to the action of antioxidants. Based on the electrochemical behavior of the studied compounds, the interaction of $\mathrm{Fe}^{3+}$ was followed by cyclic voltammetry $(\mathrm{CV})$ via the possible changes of redox peaks characteristic for $\mathrm{Fe}^{3+} / \mathrm{Fe}^{2+}$ transition after the interaction with antioxidants (if any).

Figure A1 shows the voltammograms of $0.5 \mathrm{mM}$ potassium ferricyanide in $0.1 \mathrm{M}$ $\mathrm{HClO}_{4}$ (black), of each compound at $0.5 \mathrm{mM}$ in $0.1 \mathrm{M} \mathrm{HClO}_{4}$ (blue) compared with that of the mixtures between potassium ferricyanide $(0.5 \mathrm{mM})$ and of each component $(0.5 \mathrm{mM})$ (pink). From the voltammogram of potassium ferricyanide it can be observed that the one-electron transfer process $\mathrm{Fe}^{3+} / \mathrm{Fe}^{2+}$ occurs at $0.247 \mathrm{~V} / 0.150 \mathrm{~V}$ in acidic media (red) (Figure A1; Table A1).

Each compound presents its characteristic peaks (blue line in each figure). When the mixtures are evaluated (pink line in each figure), if a decrease of redox peaks typical for $\mathrm{Fe}^{3+/} \mathrm{Fe}^{2+}$ process is noticed, due to the interaction with one compound this suggests that that compound exhibits reducing action to ferricyanide ion and as a consequence antioxidant capacity.

Meantime, the oxidation signals of compounds can be influenced by the presence of ferricyanide in the solution, being partially oxidized during the interaction with $\mathrm{Fe}^{3+}$, and consequently, the electrochemical oxidation is slower as indicated by the shift of anodic peaks to higher potentials.

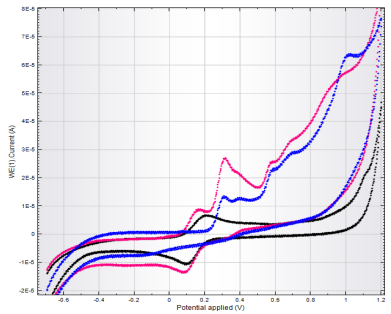

$5 \mathbf{a}$

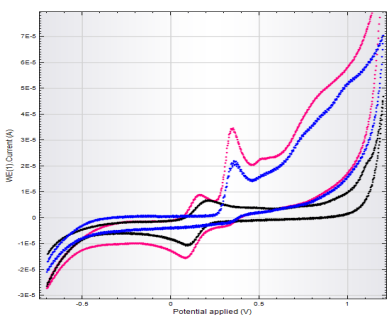

$6 a$

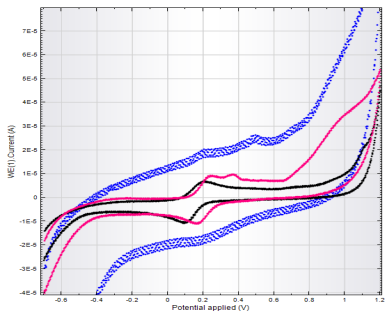

$7 \mathbf{a}$

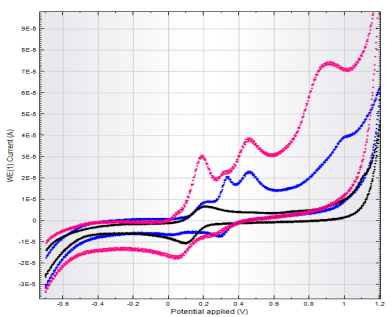

$8 \mathbf{a}$

Figure A1. Cont. 


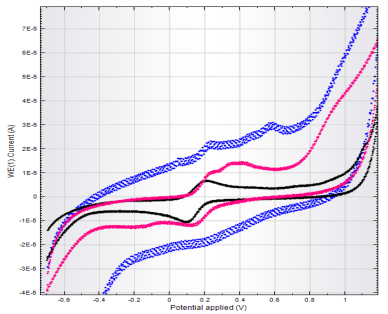

$5 b$

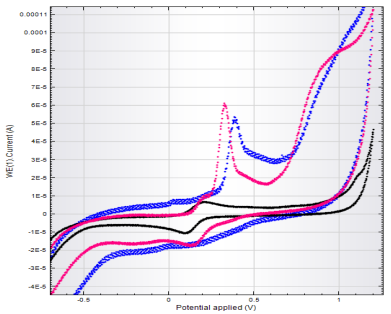

$6 b$

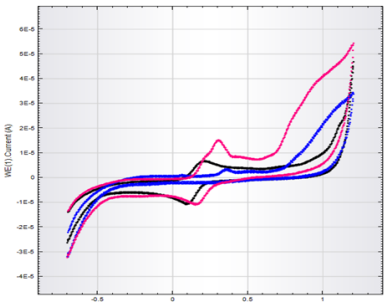

$7 \mathrm{~b}$

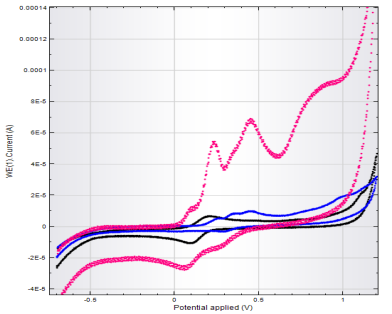

$8 b$

Figure A1. Overlapped CVs for $0.5 \mathrm{mM}$ potassium ferricyanide (black); $0.5 \mathrm{mM}$ solution of the novel synthesized compounds (blue) and of solutions with equal concentrations of $0.5 \mathrm{M}$ of ferricyanide and one compound at a time (pink) prepared in $0.1 \mathrm{M} \mathrm{HClO}_{4}$ on graphite SPE.

A different behavior can be observed again for the studied compounds, but again, $5 \mathbf{a}$ has a similar behavior with $\mathbf{5 b}$, and $\mathbf{8 a}$ with $\mathbf{8 b}$. These compounds were represented comparatively, individually, respectively in the presence of the redox probe (Figures A1-A3).

From Table A1 it can be seen the variation of the potential and intensity of the oxidation currents from one compound to another. In the case of $\mathbf{5 a}$ and $\mathbf{5 b}$, it can be observed the decrease of the oxidation signal of the redox probe when the respective compounds are in the same solution, which is in accordance with the behavior of the compounds with antioxidant action, a phenomenon that occurs simultaneously with the increase of the oxidation signals corresponding to the compounds. In the case of $\mathbf{8 a}$ and $\mathbf{8 b}$ it is observed that both show an oxidation signal positioned in the same potential range as that of the redox probe. The interaction between $\mathbf{8 a}$ or $\mathbf{8 b}$ with the redox probe causes an almost complete decrease in the oxidation signal of the redox probe, confirming the antioxidant character of the compounds, while the oxidation signals of the compounds increase significantly.

It can be concluded that $\mathbf{8 a}$ has the highest scavenging effect on ferric ion, followed by $8 \mathbf{b}, \mathbf{5 b}$ and $5 \mathbf{a}$ and that the variation of the oxidation signals of the tested compounds did not confirm the observed trend at the redox probe signal for all compounds tested. One explanation could be that almost all compounds have a signal in the potential range in which the ferric ion signal is, thus possible interference between them may occur.
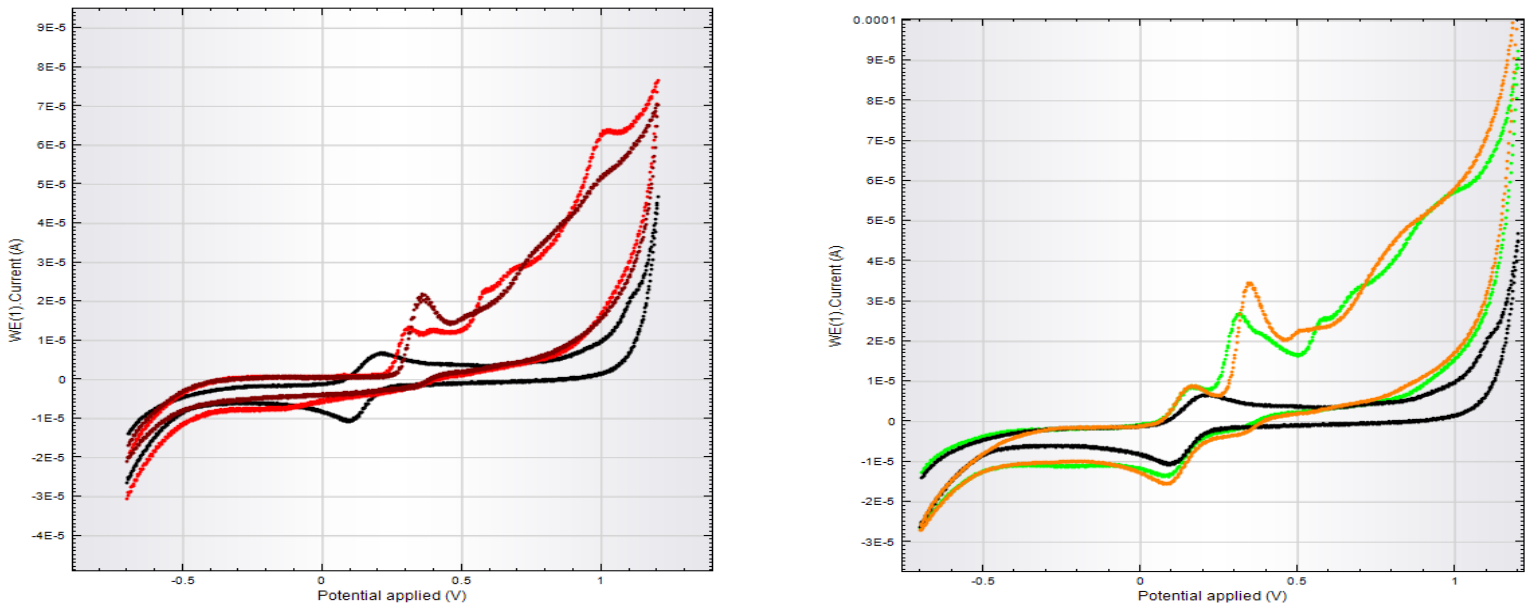

Figure A2. Left-Comparison between CVs for $0.5 \mathrm{mM}$ of potassium ferricyanide (black), $\mathbf{5 a}$ (red) and $\mathbf{5 b}$ (brown). RightComparison between CVs for $0.5 \mathrm{mM}$ of potassium ferricyanide (black); mixtures of $0.5 \mathrm{mM}$ of potassium ferricyanide and $0.5 \mathrm{mM}$ of $5 \mathbf{a}$ (light green) and $5 \mathbf{b}$ (orange). 

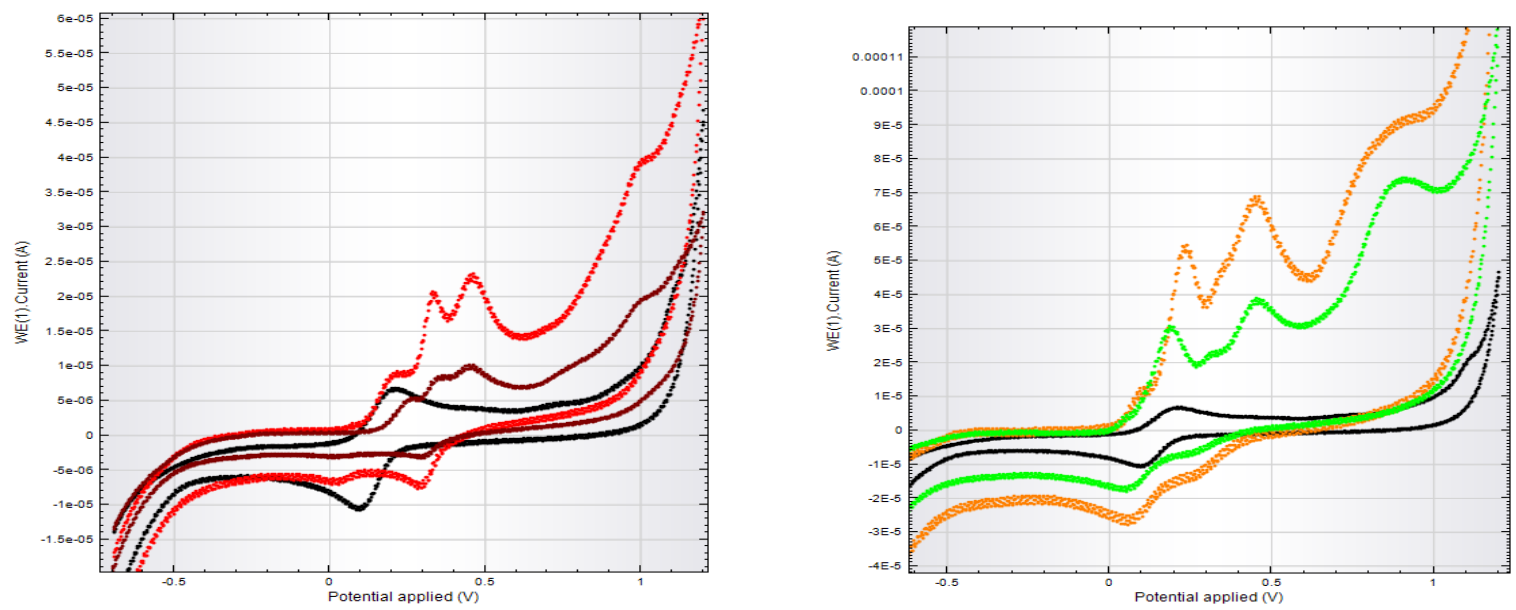

Figure A3. Left-Comparison between CVs for $0.5 \mathrm{mM}$ of: potassium ferricyanide (black); $8 \mathbf{a}$ (red) and $\mathbf{8 b}$ (brown). Right-Comparison between CVs for $0.5 \mathrm{mM}$ of potassium ferricyanide (black); and mixtures of $0.5 \mathrm{mM}$ of potassium ferricyanide and: $0.5 \mathrm{mM}$ of $\mathbf{8 a}$ (light green) and $\mathbf{8 b}$ (orange).

Table A1. Comparative presentation of the scavenging effect of the synthesized compounds on ferricyanide.

\begin{tabular}{|c|c|c|c|c|c|c|c|c|c|c|c|c|c|c|}
\hline Compound & $\begin{array}{l}E_{\text {ox }} \\
\text { (V) }\end{array}$ & $\begin{array}{c}I_{0 x} \\
(\mu \mathrm{A})\end{array}$ & $\begin{array}{l}E_{\text {ox }} \\
\text { (V) }\end{array}$ & $\begin{array}{c}I_{o x} \\
(\mu \mathrm{A})\end{array}$ & $\begin{array}{l}E_{\text {ox }} \\
\text { (V) }\end{array}$ & $\begin{array}{c}I_{o x} \\
(\mu \mathrm{A})\end{array}$ & $\begin{array}{l}E_{o x} \\
\text { (V) }\end{array}$ & $\begin{array}{c}I_{o x} \\
(\mu \mathrm{A})\end{array}$ & $\begin{array}{l}E_{\text {ox }} \\
\text { (V) }\end{array}$ & $\begin{array}{c}I_{o x} \\
(\mu \mathrm{A})\end{array}$ & $\begin{array}{l}E_{\text {red }} \\
\text { (V) }\end{array}$ & $\begin{array}{c}\mathbf{I}_{\text {red }} \\
(\mu \mathrm{A})\end{array}$ & $\begin{array}{c}E_{\text {red }} \\
\text { (V) }\end{array}$ & $\begin{array}{c}I_{\text {red }} \\
(\mu \mathrm{A})\end{array}$ \\
\hline $\mathrm{Fe}^{3+} / \mathrm{Fe}^{2+}$ & 0.198 & 6.35 & - & - & - & - & - & - & - & - & 0.095 & -7.98 & - & - \\
\hline $5 a$ & - & - & 0.308 & 8.83 & 0.573 & 5.23 & & & 0.997 & 9.78 & & & 0.318 & -1.23 \\
\hline $5 \mathrm{a}+\mathrm{Fe}^{3+} / \mathrm{Fe}^{2+}$ & 0.152 & 3.69 & 0.308 & 16.21 & 0.572 & 4.14 & & & 0.903 & 3.82 & 0.091 & -7.33 & 0.323 & -0.99 \\
\hline $5 b$ & & & 0.355 & 15.68 & & & & & & & & & 0.327 & -1.56 \\
\hline $5 b+F^{3+} / F^{2+}$ & 0.152 & 5.57 & 0.342 & 22.3 & 0.505 & 1.20 & 0.506 & 8.68 & 0.806 & 8.68 & 0.093 & -8.66 & 0.323 & -1.52 \\
\hline $6 a$ & - & - & 0.232 & 3.04 & 0.586 & 6.79 & & & & & & & & \\
\hline $6 \mathrm{a}+\mathrm{Fe}^{3+} / \mathrm{Fe}^{2+}$ & & & 0.223 & 2.74 & 0.424 & 3.82 & & & & & 0.142 & -5.88 & & \\
\hline $6 b$ & & & 0.386 & 37.55 & & & & & 0.894 & 8.86 & & & & \\
\hline $6 \mathrm{~b}+\mathrm{Fe}^{3+} / \mathrm{Fe}^{2+}$ & 0.203 & 2.48 & 0.325 & 44.78 & & & & & 0.879 & 21.84 & 0.149 & -8.26 & & \\
\hline $7 a$ & & & 0.205 & 4.37 & 0.493 & 1.95 & & & & & & & & \\
\hline $7 \mathrm{a}+\mathrm{Fe}^{3+} / \mathrm{Fe}^{2+}$ & & & 0.23 & 4.35 & 0.374 & 1.75 & & & & & 0.164 & -7.23 & & \\
\hline $7 \mathrm{~b}$ & & & 0.347 & 2.07 & & & & & 1.065 & 2.64 & & & & \\
\hline $7 \mathrm{~b}+\mathrm{Fe}^{3+} / \mathrm{Fe}^{2+}$ & 0.205 & 1.39 & 0.305 & 6.08 & & & & & 0.926 & 6.34 & 0.161 & -6.8 & & \\
\hline $8 a$ & & & 0.195 & 2.32 & 0.330 & 7.42 & 0.460 & 7.70 & 0.985 & 3.45 & & & 0.296 & -5.09 \\
\hline $8 \mathrm{a}+\mathrm{Fe}^{3+} / \mathrm{Fe}^{2+}$ & 0.072 & 0.17 & 0.186 & 17.73 & & & 0.452 & 12.93 & 0.87 & 18.64 & 0.054 & -8.37 & & \\
\hline $8 b$ & & & 0.249 & 1.02 & 0.349 & 1.76 & 0.450 & 2.29 & 0.989 & 1.17 & & & 0.303 & -1.97 \\
\hline $8 b+F^{3+} / F^{2+}$ & 0.083 & 0.34 & 0.227 & 28.09 & & & 0.449 & 28.48 & 0.79 & 15.19 & 0.079 & -8.01 & 0.279 & -2.81 \\
\hline
\end{tabular}

\section{The DPPH radical scavenging}

The radical scavenging properties of the novel compounds and the other antioxidants were determined using a stock DPPH radical solution prepared in absolute ethanol. The antioxidant samples were mixed with $\mathrm{DPPH}$ s solution and $\mathrm{HClO}_{4}$ electrolyte and incubated in the dark for $30 \mathrm{~min}$. The remaining redox activity of DPPH was measured by cycling the potential between $-0.7 \mathrm{~V}$ and $1.2 \mathrm{~V}$, with a scan rate of $0.1 \mathrm{~V} / \mathrm{s}$.

The nitrogen-centered 2-2-diphenyl-1-picrylhydrazyl radical (DPPH') based assay is one of the most commonly employed method to evaluate the ability of a compound to scavenge or neutralize free radicals based on the reduction of the radical. The electrochemical behavior of $\mathrm{DPPH}^{\cdot}$ was studied at graphite-based $\mathrm{SPE}$ in $\mathrm{HClO}_{4}$ (Figure A4) and the results showed that $\mathrm{DPPH}^{\circ}$ is reduced and oxidized in a reversible manner as indicated by the redox peaks couple located at $0.396 \mathrm{~V} / 0.333 \mathrm{~V}$.

Taking into account the redox activity of $\mathrm{DPPH}$, its diminution by an antioxidant can also be followed by $\mathrm{CV}$, which is expected to show changes in the voltammetric peaks. Figure A5 reports the electrochemical study of initial electrooxidation of DPPH and the novel compounds compared to remaining peaks after their incubation for $30 \mathrm{~min}$. The decrease of all the peaks after mixture incubation indicates the partial consumption of DPPH: 
are rather difficult to monitor.

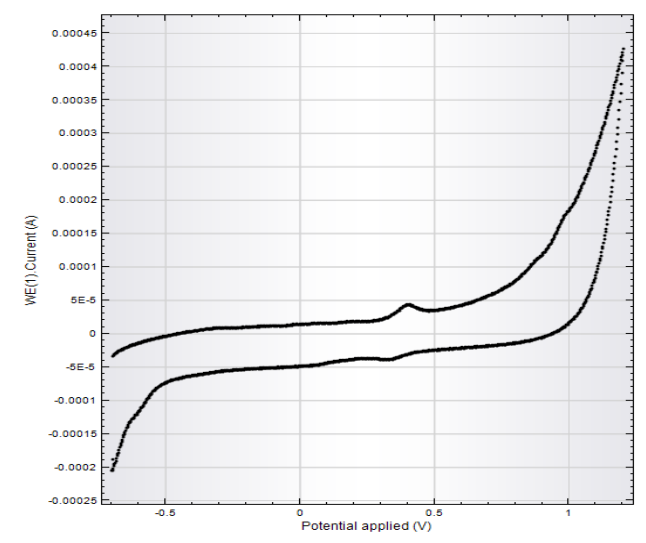

Figure A4. CV registered on graphite-based SPE in the presence of $0.5 \mathrm{mM} \mathrm{DPPH}^{\circ}$ in $0.1 \mathrm{M} \mathrm{HClO}_{4}$.

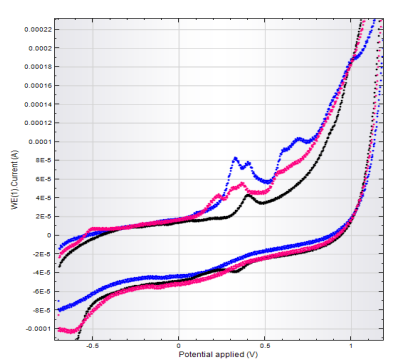

$5 a$

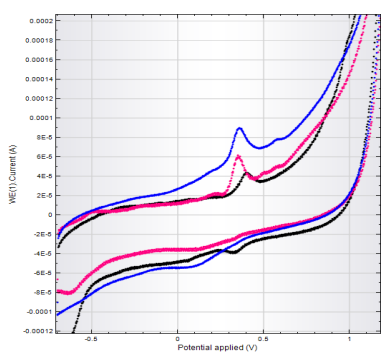

$5 b$

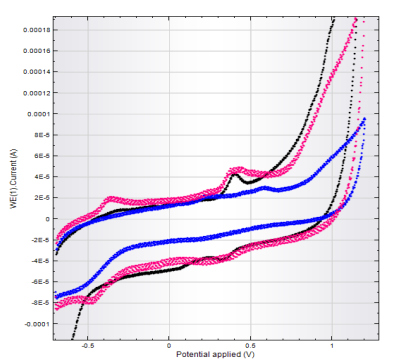

$6 a$

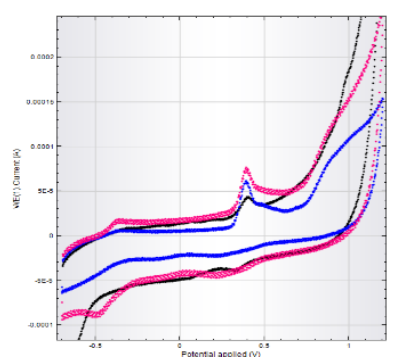

$6 b$

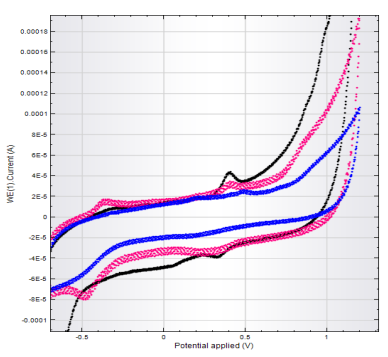

$7 a$

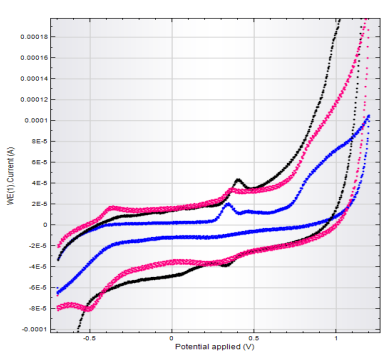

$7 \mathrm{~b}$

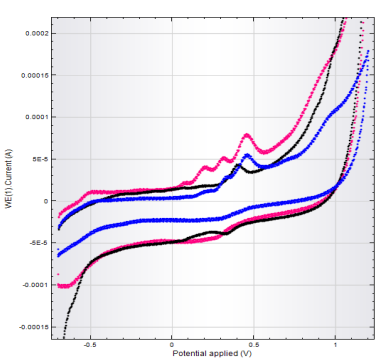

$8 a$

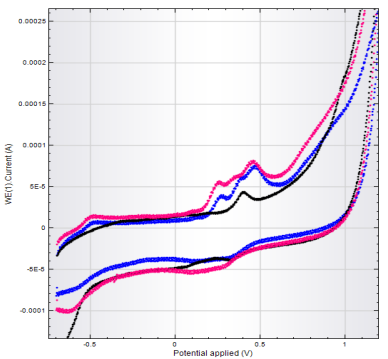

$8 b$

Figure A5. Overlapped CVs for $0.5 \mathrm{mM} \mathrm{DPPH}^{\cdot}$ (black); $0.5 \mathrm{mM}$ solution of the synthesized compounds (blue) and of solutions with equal concentrations of $0.5 \mathrm{M}$ of $\mathrm{DPPH}^{-}$and one compound at a time (pink) prepared in $0.1 \mathrm{M} \mathrm{HClO}_{4}$ on graphite SPE.

In some situations the signals of DPPH' are very difficult to read due to the signals of the compounds, but it can be observed that the most important influence on it was again from the compounds $\mathbf{8 b}, \mathbf{5 a}, \mathbf{5 b}$ and $\mathbf{8 a}$.

Table A2. Comparative presentation of the scavenging effect of the tested compounds and of some antioxidants on DPPH' radical after $30 \mathrm{~min}$ of reaction.

\begin{tabular}{|c|c|c|c|c|c|c|c|c|c|c|c|c|}
\hline Compound & $\begin{array}{l}E_{\text {ox }} \\
\text { (V) }\end{array}$ & $\begin{array}{c}I_{o x} \\
(\mu \mathrm{A})\end{array}$ & $\begin{array}{l}E_{\text {ox }} \\
\text { (V) }\end{array}$ & $\begin{array}{c}\mathbf{I}_{\mathbf{o x}} \\
(\mu \mathrm{A})\end{array}$ & $\begin{array}{l}E_{\text {ox }} \\
\text { (V) }\end{array}$ & $\begin{array}{c}\mathbf{I}_{\mathbf{o x}} \\
(\mu \mathrm{A})\end{array}$ & $\begin{array}{l}E_{\text {ox }} \\
\text { (V) }\end{array}$ & $\begin{array}{c}I_{\mathbf{o x}} \\
(\mu \mathrm{A})\end{array}$ & $\begin{array}{c}E_{\text {red }} \\
\text { (V) }\end{array}$ & $\begin{array}{c}I_{\text {red }} \\
(\mu \mathrm{A})\end{array}$ & $\begin{array}{c}E_{\text {red }} \\
\text { (V) }\end{array}$ & $\begin{array}{c}I_{\text {red }} \\
(\mu \mathrm{A})\end{array}$ \\
\hline DPPH & & & 0.396 & 16.9 & & & & & 0.333 & -7.19 & & \\
\hline $5 a$ & & & 0.339 & 43.29 & 0.598 & 20.51 & 0.987 & 15.5 & & & 0.137 & -9.59 \\
\hline 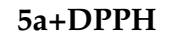 & 0.218 & 8.68 & 0.362 & 13.23 & 0.572 & 11.81 & & & & & 0.188 & -5.46 \\
\hline $5 b$ & & & 0.357 & 31.76 & & & & & & & 0.11 & -10.26 \\
\hline $5 b+D P P H$ & & & 0.349 & 33.3 & & & & & & & 0.145 & -7.56 \\
\hline
\end{tabular}


Table A2. Cont.

\begin{tabular}{|c|c|c|c|c|c|c|c|c|c|c|c|c|}
\hline Compound & $\begin{array}{l}E_{o x} \\
\text { (V) }\end{array}$ & $\begin{array}{c}I_{0 x} \\
(\mu \mathrm{A})\end{array}$ & $\begin{array}{l}E_{o x} \\
\text { (V) }\end{array}$ & $\begin{array}{c}I_{0 x} \\
(\mu \mathrm{A})\end{array}$ & $\begin{array}{l}E_{o x} \\
\text { (V) }\end{array}$ & $\begin{array}{c}\mathrm{I}_{\mathbf{0 x}} \\
(\mu \mathrm{A})\end{array}$ & $\begin{array}{l}E_{o x} \\
\text { (V) }\end{array}$ & $\begin{array}{c}\mathrm{I}_{\mathbf{0 x}} \\
(\mu \mathrm{A})\end{array}$ & $\begin{array}{l}E_{\text {red }} \\
\text { (V) }\end{array}$ & $\begin{array}{c}I_{\text {red }} \\
(\mu \mathrm{A})\end{array}$ & $\begin{array}{l}E_{\text {red }} \\
\text { (V) }\end{array}$ & $\begin{array}{c}I_{\text {red }} \\
(\mu \mathrm{A})\end{array}$ \\
\hline $6 a$ & 0.232 & 4.99 & & & 0.565 & 4.37 & & & & & 0.193 & -4.16 \\
\hline $6 a+D P P H$ & & & 0.379 & 18.21 & & & & & & & & \\
\hline $6 b$ & & & 0.391 & 47.3 & & & & & & & 0.239 & -7.045 \\
\hline $6 b+D P P H$ & & & 0.391 & 43.4 & & & & & 0.302 & -1.09 & 0.425 & -1.23 \\
\hline $7 a$ & 0.205 & 3.21 & & & 0.493 & 3.95 & & & & & 0.217 & -5.26 \\
\hline $7 a+D P P H$ & & & 0.405 & 9.24 & & & & & & & & \\
\hline $7 \mathrm{~b}$ & & & 0.342 & 15.65 & & & & & & & 0.276 & -2.54 \\
\hline $7 b+D P P H$ & & & 0.359 & 9.076 & & & & & 0.291 & -7.43 & & \\
\hline $8 a$ & 0.193 & 3.56 & 0.325 & 6.97 & 0.459 & 22.39 & 0.935 & 6.88 & & & 0.278 & -18.04 \\
\hline $8 a+D P P H$ & 0.188 & 11.53 & 0.311 & 11.18 & 0.455 & 20.68 & 0.908 & 6.39 & & & & \\
\hline $8 b$ & 0.259 & 10.92 & & & 0.47 & 29.61 & & & & & 0.127 & -3.52 \\
\hline $8 b+D P P H$ & 0.247 & 17.56 & & & 0.457 & 18.63 & & & 0.259 & -14.96 & & \\
\hline
\end{tabular}

\section{Scavenging of hydrogen peroxide}

Hydrogen peroxide $\left(\mathrm{H}_{2} \mathrm{O}_{2}\right)$ is not a free radical itself, but easily converts to free radicals like $\mathrm{OH}^{\cdot}$ in biological systems, where is then implicated as a highly damaging species in free radical pathology, capable of damaging almost every molecule of living cells.

The anodic oxidation of $\mathrm{H}_{2} \mathrm{O}_{2}$ was used to determine the antioxidant character of compounds in different samples. Gold-based SPEs purchased from Dropsens were used as working electrode for monitoring the change in the oxidation peak of hydrogen peroxide due to the addition of different amounts of the novel compounds. The oxidation signal of $\mathrm{H}_{2} \mathrm{O}_{2}$ obtained at the sweep of the potential in the range from -0.5 to $1.2 \mathrm{~V}$ on the gold electrode can be observed in Figure A6. The scavenging abilities of compounds from 1 to 8 on hydroxyl radical are compared in this figure. The addition of an antioxidant, by its ability to consume $\mathrm{H}_{2} \mathrm{O}_{2}$, determines the decrease of anodic peak characteristic for $\mathrm{H}_{2} \mathrm{O}_{2}$. It could be claimed that antioxidants act by reacting with the dissociated hydrogen peroxide and thus decreasing its concentration, producing a decrease in the anodic peak current that can be related to the antioxidant activity. However, this implies that the antioxidant must react with $\mathrm{H}_{2} \mathrm{O}_{2}$ in the solution.

Diverse hypotheses were proposed in literature in order to support the role of specific structural components as requisites for radical scavenging and antioxidant activity most of which refer to the configuration and total number of hydroxyl groups. It can be observed that $8 \mathbf{a}$ has the highest scavenging effect on $\mathrm{H}_{2} \mathrm{O}_{2}$, followed by $\mathbf{8 b}, \mathbf{5 a}$ and $\mathbf{5 b}$.

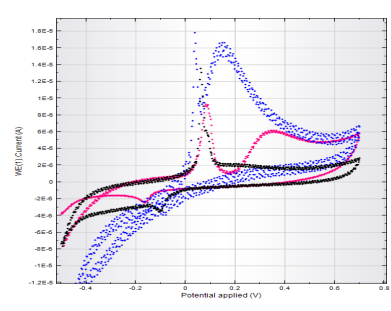

$5 a$

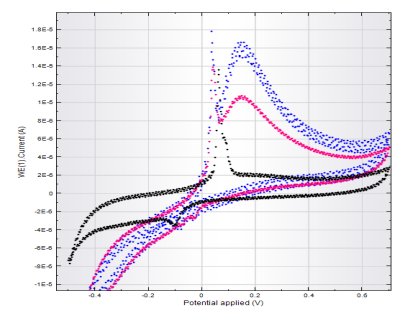

$6 a$

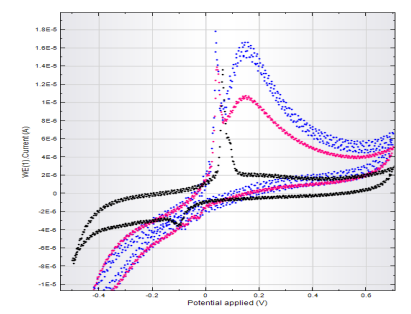

7a

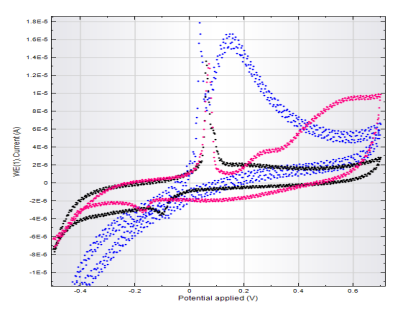

$8 a$

Figure A6. Cont. 


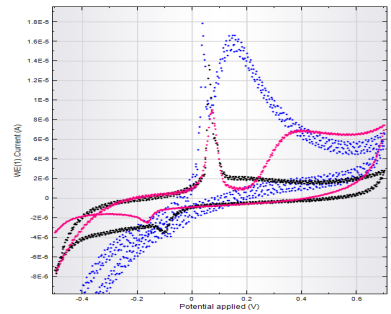

$5 b$

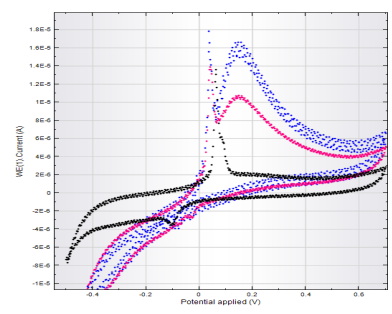

$6 b$

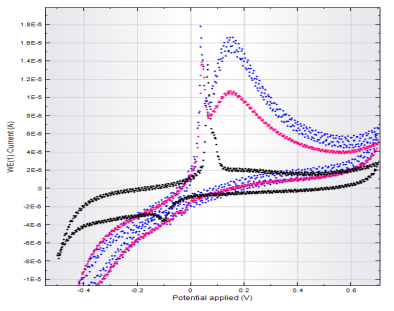

$7 \mathbf{b}$

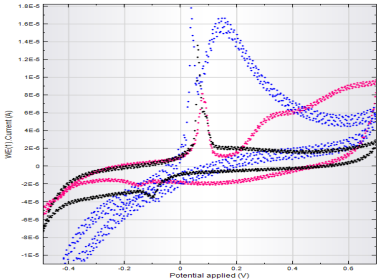

$8 b$

Figure A6. Overlapped CVs for the oxidation signal obtained for $0.5 \mathrm{mM} \mathrm{H}_{2} \mathrm{O}_{2}$ in the absence (blue) and in the presence $0.5 \mathrm{mM}$ of the novel synthesized compounds (pink) prepared in $0.1 \mathrm{M} \mathrm{KCl}$ on Au SPE. Black line: CV recorded in $0.1 \mathrm{M} \mathrm{KCl}$.

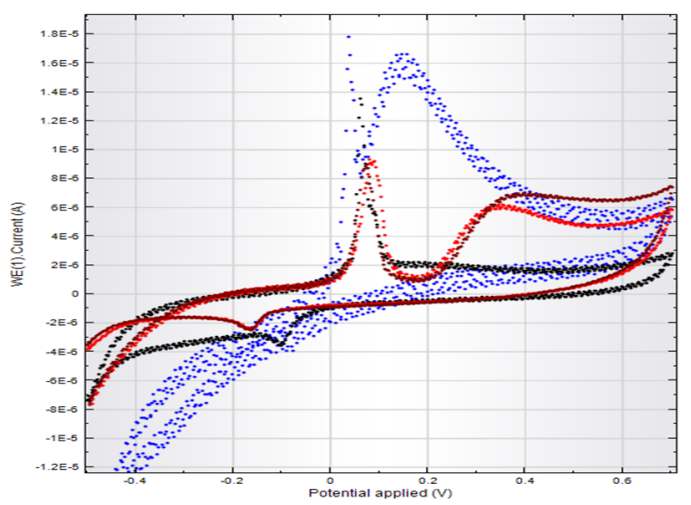

Figure A7. Overlapped CVs for the oxidation signal obtained for $0.5 \mathrm{mM} \mathrm{H}_{2} \mathrm{O}_{2}$ in the absence (blue) and in the presence of $0.5 \mathrm{mM}$ of the novel synthesized compounds: $5 \mathbf{a}$ (red) and $\mathbf{5 b}$ (brown) prepared in $0.1 \mathrm{M} \mathrm{KCl}$ on $\mathrm{Au}$ SPE. Black line: $\mathrm{CV}$ recorded in $0.1 \mathrm{M} \mathrm{KCl}$.

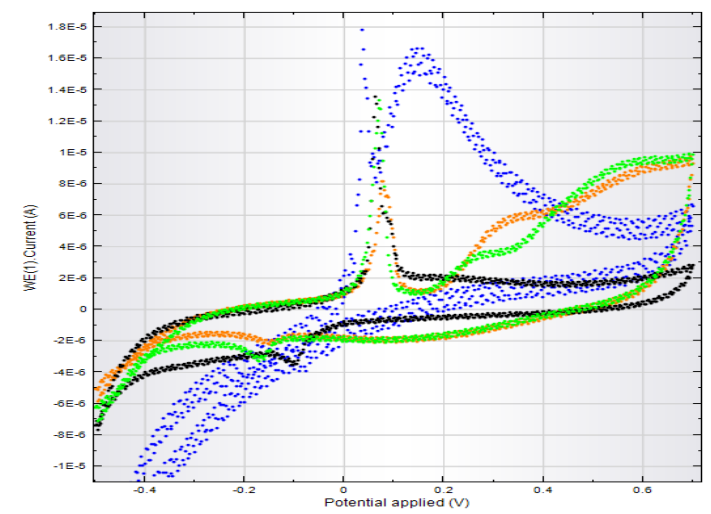

Figure A8. Overlapped CVs for the oxidation signal obtained for $0.5 \mathrm{mM} \mathrm{H}_{2} \mathrm{O}_{2}$ in the absence (blue) and in the presence of $0.5 \mathrm{mM}$ of the novel synthesized compounds: $8 \mathbf{a}$ (green) and $\mathbf{8 b}$ (orange) prepared in $0.1 \mathrm{M} \mathrm{KCl}$ on Au SPE. Black line: CV recorded in $0.1 \mathrm{M} \mathrm{KCl}$.

\section{2,2,6,6-tetramethylpiperidinyl-1-oxy (TEMPO) scavenging}

TEMPO (2,2,6,6-tetramethylpiperidine-N-oxyl) is a stable organic nitroxide radical that has been reported to scavenge carbon-centered radicals. The $\mathrm{CV}$ of TEMPO in $\mathrm{HClO}_{4}$ (Figure A9) reveals its reversible one-electron transfer process with oxidation peak at $0.27 \mathrm{~V}$ corresponding to the oxidation of TEMPO to oxoammonium species, accompanied by a cathodic peak at $0.20 \mathrm{~V}$ corresponding to the reduction of electrochemically generated oxoammonium. 


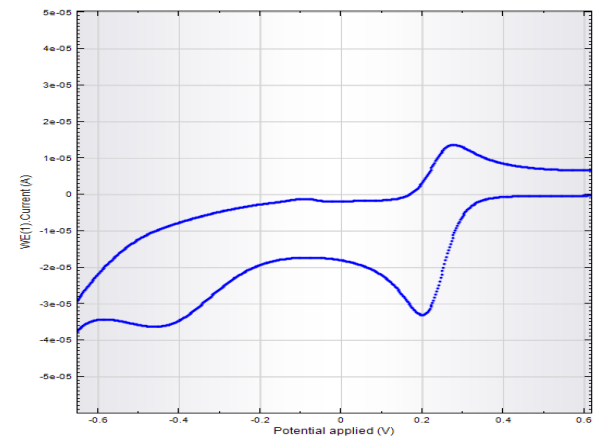

Figure A9. CV registered on graphite-based SPE in the presence of $2 \mathrm{mM}$ TEMPO in $0.1 \mathrm{M} \mathrm{HClO}_{4}$.

Differential pulse voltammetry (DPV) was then applied in order to evaluate the antioxidant effectiveness of the novel compounds through their ability to scavenge the free radical species. Figure A10-left shows the DPVs of $2 \mathrm{mM}$ TEMPO and of $2 \mathrm{mM}$ TEMPO incubated for one hour with different concentrations of ascorbic acid. It can be observed that the anodic peak of TEMPO decreases when increasing the concentration of ascorbic acid, used as control antioxidant.
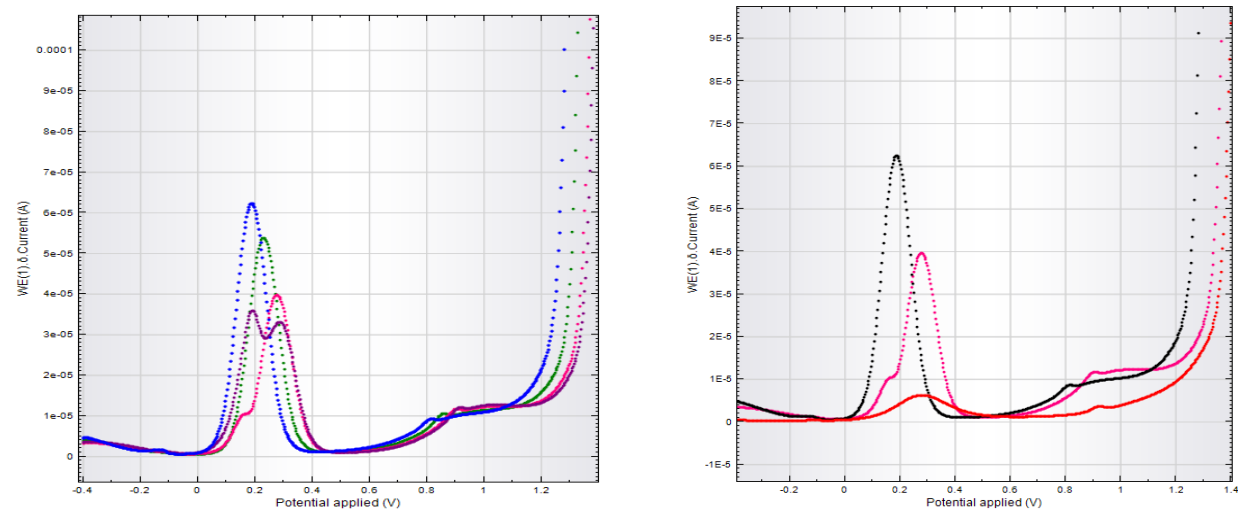

Figure A10. Left: DPV registered on graphite-based SPE in the presence of $2 \mathrm{mM}$ TEMPO (blue) and for $2 \mathrm{mM}$ TEMPO after one hour incubation with different concentrations of ascorbic acid: $0.25 \mathrm{mM}$ (green); $0.5 \mathrm{mM}$ (pink ) 1mM (purple). Right: DPVs registered on graphite-based SPE in the presence of $2 \mathrm{mM}$ TEMPO (black); $0.5 \mathrm{mM}$ ascorbic acid (red) and for $2 \mathrm{mM}$ TEMPO after one hour incubation with $0.5 \mathrm{mM}$ (pink) of ascorbic acid. Solutions are prepared in $0.1 \mathrm{M} \mathrm{HClO}_{4}$.

Similar effect was followed in the case of the studied compounds (Figure A11).

The corresponding oxidation signal for TEMPO does not decrease after one hour of reaction with compounds $\mathbf{6 a}, \mathbf{7 a}, \mathbf{6 b}$ and $7 \mathbf{b}$. These compounds only cause the signal shift to higher potential values. In contrast, compounds $\mathbf{5 a}, \mathbf{8 a}, \mathbf{5 b}$ and $\mathbf{8 b}$ cause both the signal shift to higher oxidation potentials and its decrease, this behavior being similar to that observed in the case of ascorbic acid, the control antioxidant.

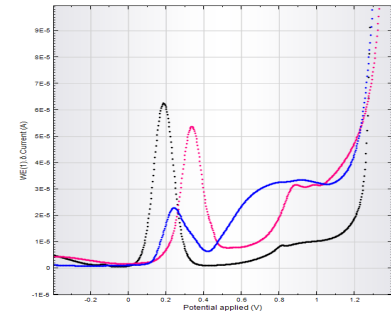

$5 a$

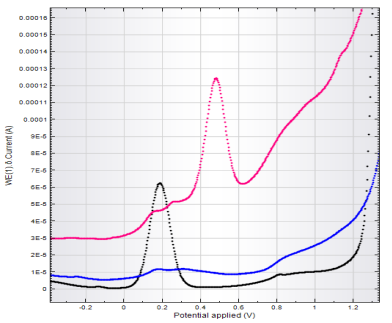

$6 a$

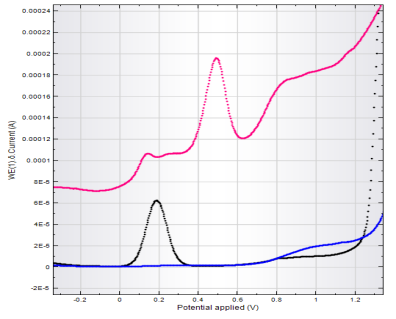

$7 \mathbf{a}$

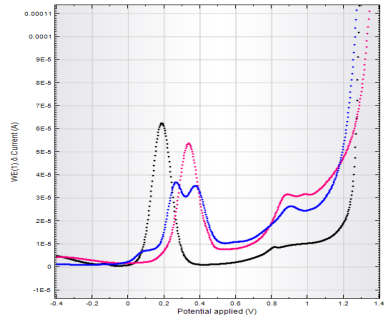

$8 a$

Figure A11. Cont. 


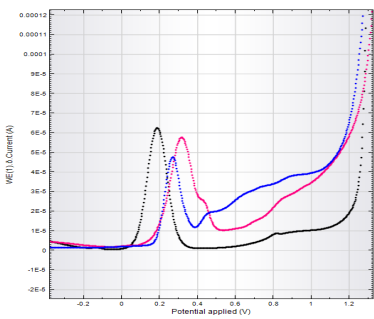

$5 \mathbf{b}$

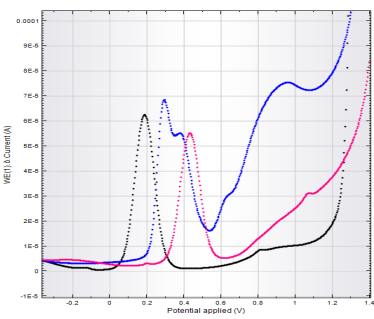

$6 b$

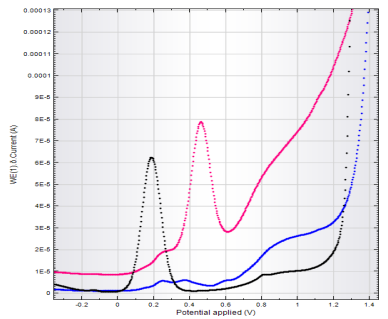

$7 \mathrm{~b}$

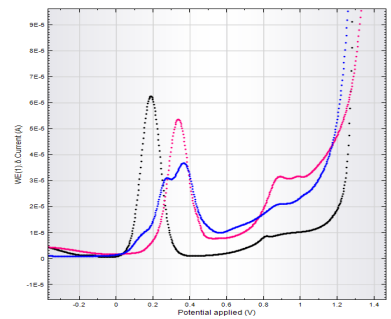

$8 b$

Figure A11. Overlapped DPVs for the oxidation signal obtained for $0.5 \mathrm{mM}$ of the novel synthesized compounds (blue); $2 \mathrm{mM}$ TEMPO (black) and after one hour incubation with $0.5 \mathrm{mM}$ of the novel synthesized compounds (pink) on graphitebased SPE. Solutions were prepared in $0.1 \mathrm{M} \mathrm{HClO}_{4}$.

\section{References}

1. Sharifi-Rad, M.; Anil Kumar, N.V.; Zucca, P.; Varoni, E.M.; Dini, L.; Panzarini, E.; Rajkovic, J.; Tsouh Fokou, P.V.; Azzini, E.; Peluso, I.; et al. Lifestyle, Oxidative Stress, and Antioxidants: Back and Forth in the Pathophysiology of Chronic Diseases. Front. Physiol. 2020, 11, 694. [CrossRef] [PubMed]

2. Pizzino, G.; Irrera, N.; Cucinotta, M.; Pallio, G.; Mannino, F.; Arcoraci, V.; Squadrito, F.; Altavilla, D.; Bitto, A. Oxidative Stress: Harms and Benefits for Human Health. Oxidative Med. Cell. Longev. 2017, 2017, 1-13. [CrossRef]

3. Mic, M.; Pîrnău, A.; Floare, C.G.; Marc, G.; Franchini, A.H.; Oniga, O.; Vlase, L.; Bogdan, M. Synthesis and molecular interaction study of a diphenolic hidrazinyl-thiazole compound with strong antioxidant and antiradical activity with HSA. J. Mol. Struct. 2021, 1244, 131278. [CrossRef]

4. Grozav, A.; Porumb, I.-D.; Găină, L.; Filip, L.; Hanganu, D. Cytotoxicity and Antioxidant Potential of Novel 2-(2-((1H-indol5yl)methylene)-hydrazinyl)-thiazole Derivatives. Molecules 2017, 22, 260. [CrossRef]

5. Jia, Y.; He, Y.; Lu, F. The structure-antioxidant activity relationship of dehydrodiferulates. Food Chem. 2018, 269, 480-485. [CrossRef] [PubMed]

6. Bonner, M.Y.; Arbiser, J.L. The antioxidant paradox: What are antioxidants and how should they be used in a therapeutic context for cancer. Future Med. Chem. 2014, 6, 1413-1422. [CrossRef] [PubMed]

7. Li, X.; Xie, Y.; Xie, H.; Yang, J.; Chen, D. $\pi-\pi$ Conjugation Enhances Oligostilbene's Antioxidant Capacity: Evidence from $\alpha$-Viniferin and Caraphenol A. Molecules 2018, 23, 694. [CrossRef] [PubMed]

8. Arshad, A.; Osman, H.; Bagley, M.C.; Lam, C.K.; Mohamad, S.; Zahariluddin, A.S.M. Synthesis and antimicrobial properties of some new thiazolyl coumarin derivatives. Eur. J. Med. Chem. 2011, 46, 3788-3794. [CrossRef]

9. Makam, P.; Kankanala, R.; Prakash, A.; Kannan, T. 2-(2-Hydrazinyl)thiazole derivatives: Design, synthesis and in vitro antimycobacterial studies. Eur. J. Med. Chem. 2013, 69, 564-576. [CrossRef] [PubMed]

10. Makam, P.; Thakur, P.K.; Kannan, T. In vitro and in silico antimalarial activity of 2-(2-hydrazinyl)thiazole derivatives. Eur. J. Pharm. Sci. 2014, 52, 138-145. [CrossRef]

11. Bouarab-Chibane, L.; Forquet, V.; Lantéri, P.; Clément, Y.; Léonard-Akkari, L.; Oulahal, N.; Degraeve, P.; Bordes, C. Antibacterial Properties of Polyphenols: Characterization and QSAR (Quantitative Structure-Activity Relationship) Models. Front. Microbiol. 2019, 10, 829. [CrossRef] [PubMed]

12. Teodoro, G.R.; Ellepola, K.; Seneviratne, C.J.; Koga-Ito, C.Y. Potential Use of Phenolic Acids as Anti-Candida Agents: A Review. Front. Microbiol. 2015, 6, 1420. [CrossRef]

13. Núñez-Montenegro, A.; Carballo, R.; Abram, U.; Vázquez-López, E.M. Preparation and characterization of rhenium(I) complexes with thiosemicarbazone ligands derived from resorcinol. Polyhedron 2013, 65, 221-228. [CrossRef]

14. Alam, M.S.; Ahmed, J.U.; Lee, D.-U. Synthesis, Antibacterial, Antioxidant Activity and QSAR Studies of Novel 2Arylidenehydrazinyl-4-arylthiazole Analogues. Chem. Pharm. Bull. 2014, 62, 1259-1268. [CrossRef] [PubMed]

15. Pop, B.; Ionuț, I.; Marc, G.; Vodnar, D.C.; Pîrnău, A.; Vlase, L.; Oniga, O. Development of new 2-methyl-4-salicylamide thiazole derivatives: Synthesis, antimicrobial activity evaluation, lipophilicity and molecular docking study. Farmacia 2021, 69, 724-731. [CrossRef]

16. Re, R.; Pellegrini, N.; Proteggente, A.; Pannala, A.; Yang, M.; Rice-Evans, C. Antioxidant activity applying an improved ABTS radical cation decolorization assay. Free Radic. Biol. Med. 1999, 26, 1231-1237. [CrossRef]

17. Marc, G.; Stana, A.; Oniga, S.D.; Pîrnău, A.; Vlase, L.; Oniga, O. New Phenolic Derivatives of Thiazolidine-2,4-dione with Antioxidant and Antiradical Properties: Synthesis, Characterization, In Vitro Evaluation, and Quantum Studies. Molecules 2019, 24, 2060. [CrossRef] [PubMed]

18. Brand-Williams, W.; Cuvelier, M.E.; Berset, C. Use of a free radical method to evaluate antioxidant activity. LWT Food Sci. Technol. 1995, 28, 25-30. [CrossRef] 
19. Bedlovičová, Z.; Strapáč, I.; Baláž, M.; Salayová, A. A Brief Overview on Antioxidant Activity Determination of Silver Nanoparticles. Molecules 2020, 25, 3191. [CrossRef] [PubMed]

20. Hamada, N.; Abdo, N. Synthesis, Characterization, Antimicrobial Screening and Free-Radical Scavenging Activity of Some Novel Substituted Pyrazoles. Molecules 2015, 20, 10468-10486. [CrossRef] [PubMed]

21. Hellal, K.; Maulidiani, M.; Ismail, I.S.; Tan, C.P.; Abas, F. Antioxidant, $\alpha$-Glucosidase, and Nitric Oxide Inhibitory Activities of Six Algerian Traditional Medicinal Plant Extracts and 1H-NMR-Based Metabolomics Study of the Active Extract. Molecules 2020, 25, 1247. [CrossRef] [PubMed]

22. Alam, M.N.; Bristi, N.J.; Rafiquzzaman, M. Review on in vivo and in vitro methods evaluation of antioxidant activity. Saudi Pharm. J. 2013, 21, 143-152. [CrossRef]

23. Benzie, I.F.F.; Strain, J.J. Ferric reducing/antioxidant power assay: Direct measure of total antioxidant activity of biological fluids and modified version for simultaneous measurement of total antioxidant power and ascorbic acid concentration. In Methods in Enzymology; Packer, L., Ed.; Academic Press: Cambridge, MA, USA, 1999; pp. 15-27.

24. Baig, H.; Ahmed, D.; Zara, S.; Asghar, M.N. In vitro Evaluation of Antioxidant Properties of Different Solvent Extracts of Rumex acetosella Leaves. Orient. J. Chem. 2011, 27, 1509-1516.

25. Stana, A.; Vodnar, D.C.; Marc, G.; Benedec, D.; Tiperciuc, B.; Tamaian, R.; Oniga, O. Antioxidant activity and antibacterial evaluation of new thiazolin-4-one derivatives as potential tryptophanyl-tRNA synthetase inhibitors. J. Enzym. Inhib. Med. Chem. 2019, 34, 898-908. [CrossRef]

26. Manojlovic, N.T.; Vasiljevic, P.J.; Maskovic, P.Z.; Juskovic, M.; Bogdanovic-Dusanovic, G. Chemical Composition, Antioxidant, and Antimicrobial Activities of Lichen Umbilicaria cylindrica (L.) Delise (Umbilicariaceae). Evid. Based Complement. Altern. Med. 2012, 2012, 1-8. [CrossRef] [PubMed]

27. Cesari, L.; Mutelet, F.; Canabady-Rochelle, L. Antioxidant properties of phenolic surrogates of lignin depolymerisation. Ind. Crops Prod. 2019, 129, 480-487. [CrossRef]

28. Wu, H.-C.; Shiau, C.-Y.; Chen, H.-M.; Chiou, T.-K. Antioxidant activities of carnosine, anserine, some free amino acids and their combination. J. Food Drug Anal. 2020, 11. [CrossRef]

29. Suresh Kumar, G.S.; Muthu Prabhu, A.; Bhuvanesh, N. Studies on the self-catalyzed Knoevenagel condensation, characterization, DPPH radical scavenging activity, cytotoxicity, and molecular properties of 5-arylidene-2,2-dimethyl-1,3-dioxane-4,6-diones using single crystal XRD and DFT techniques. J. Mol. Struct. 2014, 1075, 166-177. [CrossRef]

30. Antonijević, M.R.; Simijonović, D.M.; Avdović, E.H.; Ćirić, A.; Petrović, Z.D.; Marković, J.D.; Stepanić, V.; Marković, Z.S. Green One-Pot Synthesis of Coumarin-Hydroxybenzohydrazide Hybrids and Their Antioxidant Potency. Antioxidants 2021, $10,1106$. [CrossRef] [PubMed]

31. Hernández-Vázquez, E.; Castañeda-Arriaga, R.; Ramírez-Espinosa, J.J.; Medina-Campos, O.N.; Hernández-Luis, F.; Chaverri, J.P.; Estrada-Soto, S. 1,5-Diarylpyrazole and vanillin hybrids: Synthesis, biological activity and DFT studies. Eur. J. Med. Chem. 2015, 100, 106-118. [CrossRef]

32. Pop, C.E.; Pârvu, M.; Arsene, A.L.; Pârvu, A.E.; Vodnar, D.C.; Tarcea, M.; Toiu, A.M.; Vlase, L. Investigation of antioxidant and antimicrobial potential of some extracts from hedera helix L. Farmacia 2017, 65, 624-629.

33. Macavei, S.G.; Suciu, M.; Craciunescu, I.; Barbu-Tudoran, L.; Tripon, S.C.; Balan, R. Hyperthermia effects on normal and tumor skin cells. Ann. Rom. Soc. Cell Biol. 2016, 21, 11-21.

34. Ciorîță, A.; Zăgrean-Tuza, C.; Moț, A.C.; Carpa, R.; Pârvu, M. The Phytochemical Analysis of Vinca L. Species Leaf Extracts Is Correlated with the Antioxidant, Antibacterial, and Antitumor Effects. Molecules 2021, 26, 3040. [CrossRef]

35. Grozav, A.; Găină, L.; Pileczki, V.; Crisan, O.; Silaghi-Dumitrescu, L.; Therrien, B.; Zaharia, V.; Berindan-Neagoe, I. The Synthesis and Antiproliferative Activities of New Arylidene-Hydrazinyl-Thiazole Derivatives. Int. J. Mol. Sci. 2014, 15, $22059-22072$. [CrossRef] [PubMed]

36. Toma, V.A.; Farcaș, A.D.; Roman, I.; Sevastre, B.; Hathazi, D.; Scurtu, F.; Damian, G.; Silaghi-Dumitrescu, R. Comparative In Vivo Effects of Hemoglobin-Based Oxygen Carriers (HBOC) with Varying Prooxidant and Physiological Reactivity. PLoS ONE 2016, 11, e0153909. [CrossRef] [PubMed]

37. Toma, V.A.; Tigu, A.B.; Farcaș, A.D.; Sevastre, B.; Taulescu, M.; Gherman, A.M.R.; Roman, I.; Fischer-Fodor, E.; Pârvu, M. New Aspects Towards a Molecular Understanding of the Allicin Immunostimulatory Mechanism via Colec12, MARCO, and SCARB1 Receptors. Int. J. Mol. Sci. 2019, 20, 3627. [CrossRef] [PubMed]

38. Daina, A.; Zoete, V. A BOILED-Egg To Predict Gastrointestinal Absorption and Brain Penetration of Small Molecules. Chem. Med. Chem. 2016, 11, 1117-1121. [CrossRef]

39. Ertl, P.; Rohde, B.; Selzer, P. Fast calculation of molecular polar surface area as a sum of fragment-based contributions and its application to the prediction of drug transport properties. J. Med. Chem. 2000, 43, 3714-3717. [CrossRef] [PubMed]

40. Daina, A.; Michielin, O.; Zoete, V. SwissADME: A free web tool to evaluate pharmacokinetics, drug-likeness and medicinal chemistry friendliness of small molecules. Sci. Rep. 2017, 7, 42717. [CrossRef]

41. Zhao, Y.H.; Abraham, M.H.; Le, J.; Hersey, A.; Luscombe, C.N.; Beck, G.; Sherborne, B.; Cooper, I. Rate-limited steps of human oral absorption and QSAR studies. Pharm. Res. 2002, 19, 1446-1457. [CrossRef] [PubMed]

42. Lipinski, C.A.; Lombardo, F.; Dominy, B.W.; Feeney, P.J. Experimental and computational approaches to estimate solubility and permeability in drug discovery and development settings. Adv. Drug Deliv. Rev. 2001, 46, 3-26. [CrossRef] 
43. Pan, X.; Wang, H.; Li, C.; Zhang, J.Z.H.; Ji, C. MolGpka: A Web Server for Small Molecule pKa Prediction Using a GraphConvolutional Neural Network. J. Chem. Inf. Model. 2021, 61, 3159-3165. [CrossRef]

44. Santos, J.S.; Alvarenga Brizola, V.R.; Granato, D. High-throughput assay comparison and standardization for metal chelating capacity screening: A proposal and application. Food Chem. 2017, 214, 515-522. [CrossRef] [PubMed]

45. Sánchez-Marzo, N.; Lozano-Sánchez, J.; Cádiz-Gurrea, M.d.l.L.; Herranz-López, M.; Micol, V.; Segura-Carretero, A. Relationships between Chemical Structure and Antioxidant Activity of Isolated Phytocompounds from Lemon Verbena. Antioxidants 2019, 8, 324. [CrossRef] [PubMed]

46. Aree, T. $\beta$-Cyclodextrin Inclusion Complexes with Catechol-Containing Antioxidants Protocatechuic Aldehyde and Protocatechuic Acid-An Atomistic Perspective on Structural and Thermodynamic Stabilities. Molecules 2021, 26, 3574. [CrossRef] [PubMed]

47. Smolyaninov, I.V.; Pitikova, O.V.; Korchagina, E.O.; Poddel'sky, A.I.; Fukin, G.K.; Luzhnova, S.A.; Tichkomirov, A.M.; Ponomareva, E.N.; Berberova, N.T. Catechol thioethers with physiologically active fragments: Electrochemistry, antioxidant and cryoprotective activities. Bioorg. Chem. 2019, 89, 103003. [CrossRef]

48. Daina, A.; Michielin, O.; Zoete, V. iLOGP: A Simple, Robust, and Efficient Description of n-Octanol/Water Partition Coefficient for Drug Design Using the GB/SA Approach. J. Chem. Inf. Model. 2014, 54, 3284-3301. [CrossRef] [PubMed]

49. Cheng, T.; Zhao, Y.; Li, X.; Lin, F.; Xu, Y.; Zhang, X.; Li, Y.; Wang, R.; Lai, L. Computation of Octanol-Water Partition Coefficients by Guiding an Additive Model with Knowledge. J. Chem. Inf. Model. 2007, 47, 2140-2148. [CrossRef]

50. Wildman, S.A.; Crippen, G.M. Prediction of Physicochemical Parameters by Atomic Contributions. J. Chem. Inf. Comput. Sci. 1999, 39, 868-873. [CrossRef]

51. Moriguchi, I.; Hirono, S.; Liu, Q.; Nakagome, I.; Matsushita, Y. Simple Method of Calculating Octanol/Water Partition Coefficient. Chem. Pharm. Bull. 1992, 40, 127-130. [CrossRef] 